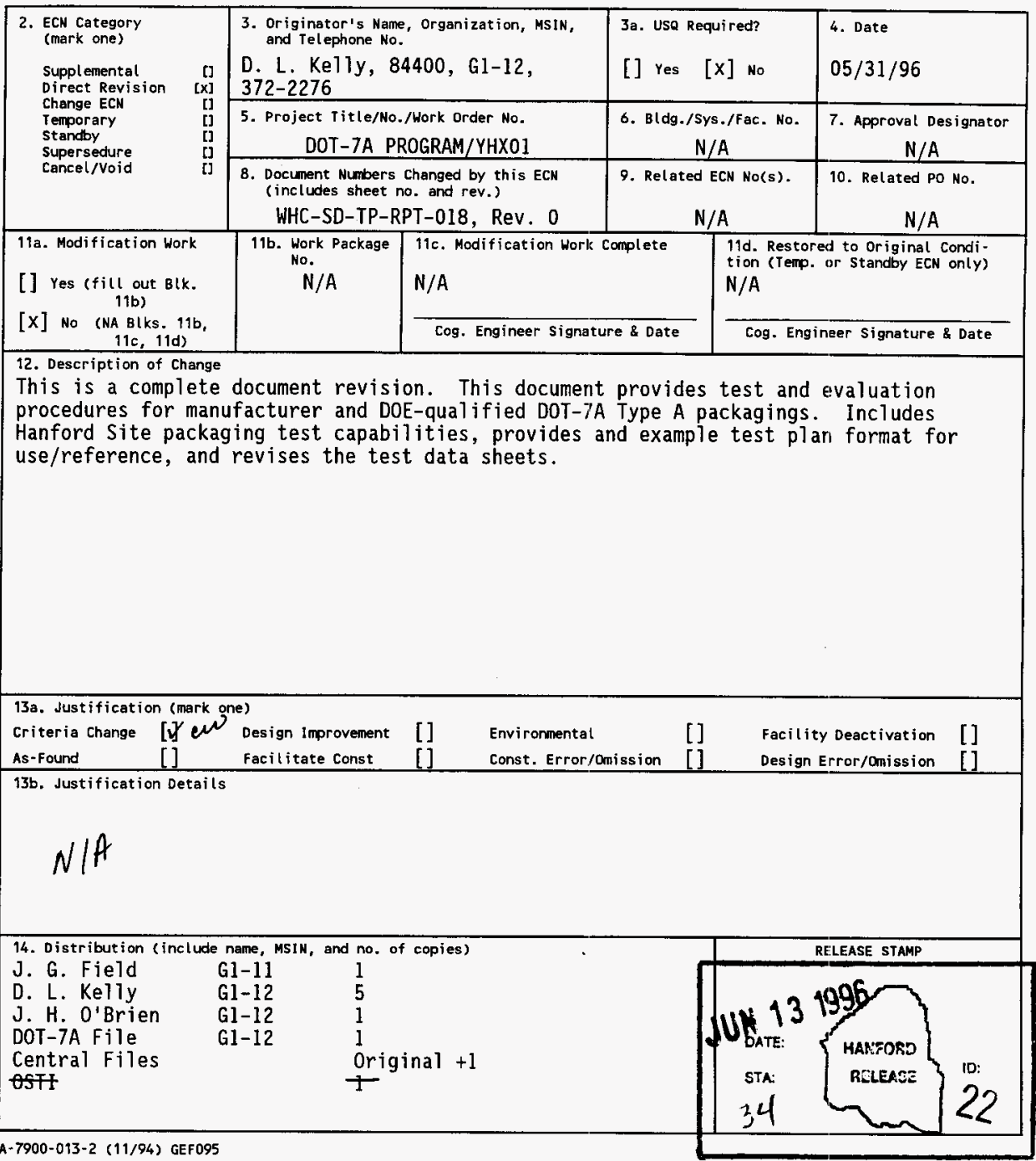




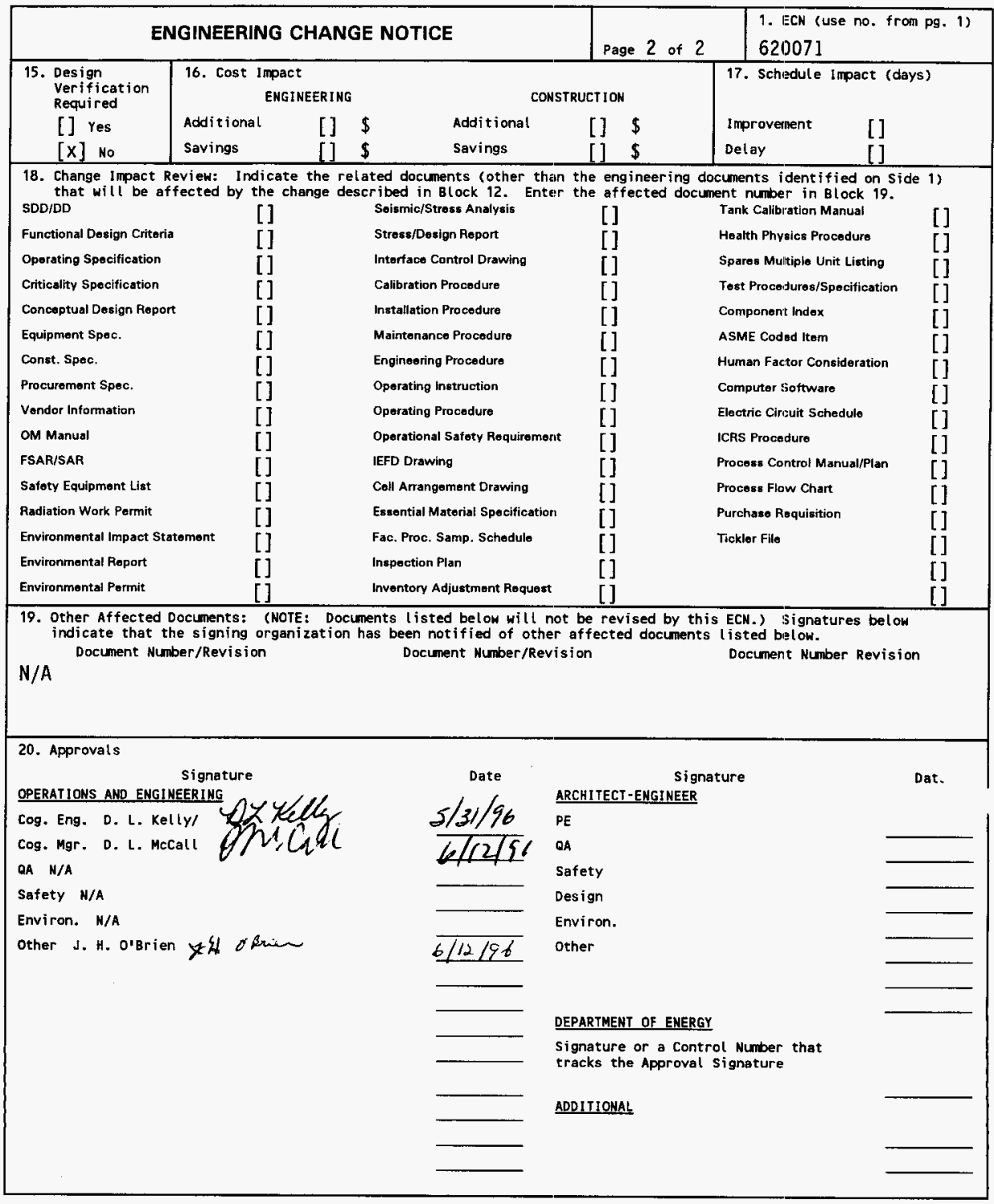




\title{
DOT-7A TYPE A PACKAGING TEST AND EVALUATION PROCEDURE
}

\author{
D. L. Kelly
}

Westinghouse Hanford Company, Richland, WA 99352

U.S. Department of Energy Contract DE-AC06-87RL10930

$\begin{array}{llll}\text { EDT/ECN: } & 620071 & \text { UC: } 722 & \\ \text { Org Code: } & 84400 & \text { Charge Code: } & \text { YHXO1 } \\ \text { B\&R Code: } & \text { HA0120000 } & \text { Tota1 Pages: } 84\end{array}$

Key Words: Test, evaluation, DOT-7A, Type A, package, packaging, radioactive material

Abstract: The purpose of this document is to provide guidance for qualifying a DOT-7A Type A packaging for use. WHC qualifies DOT-7A packaging for two purposes. The first is to provide packages for use by WHC (manufacturer-qualified). The second is to provide a contracted service in support of DOE/EM-76 (DOE-qualified). This document includes descriptions of the performance tests, the personnel involved and their qualifications, appropriate safety and quality assurance considerations, and the procedures to be followed when WHC performs the tests (either as the manufacturer, or on behalf of the DOE's certification program).

TRADEMARK OISCLAIMER. Reference herein to any specific commercial product, process, or service by trade name, tradenark, manufacturer, or otherwise, does not necessarily constitute or imply its endorsement, recommendation, or favoring by the United States Government or any agency thereof or its contractors or subcontractors.

Printed in the United States of Anerica. To obtain copies of this document, contact: WHC/BCS Document Control Services, P.O. Box 1970, Mailstop H6-08, Richland WA 99352, Phone (509) 372-2420; Fax (509) 376-4989.
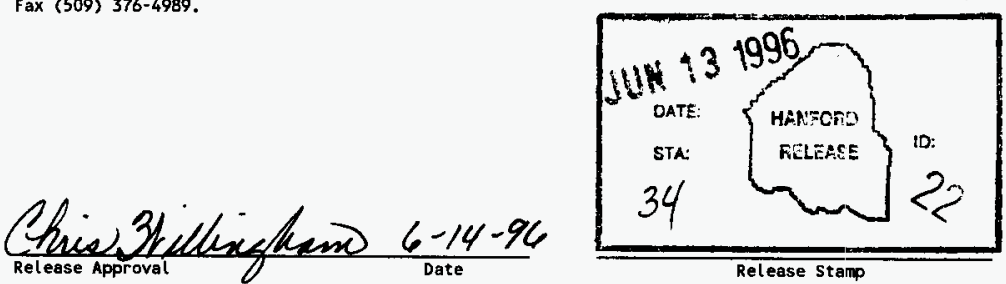

Approved for Public Release 


\section{RECORD OF REVISION}

(2) Title

DOT-7A TYPE A PACKAGING TEST AND EVALUATION PROCEDURE

CHANGE CONTROL RECORD

(3) Revision (4) Description of Change - Replace, Add, and Delete Pages (7) EDT \#608456

ECN \#620071

15 Full document revision. Provides test and evaluation procedures for manufacturer and DOE-qualified DOT-7A Type A packagings. Includes Hanford Site packaging test capabilities, provides an example test plan format for use/reference, and revises the test data sheets.

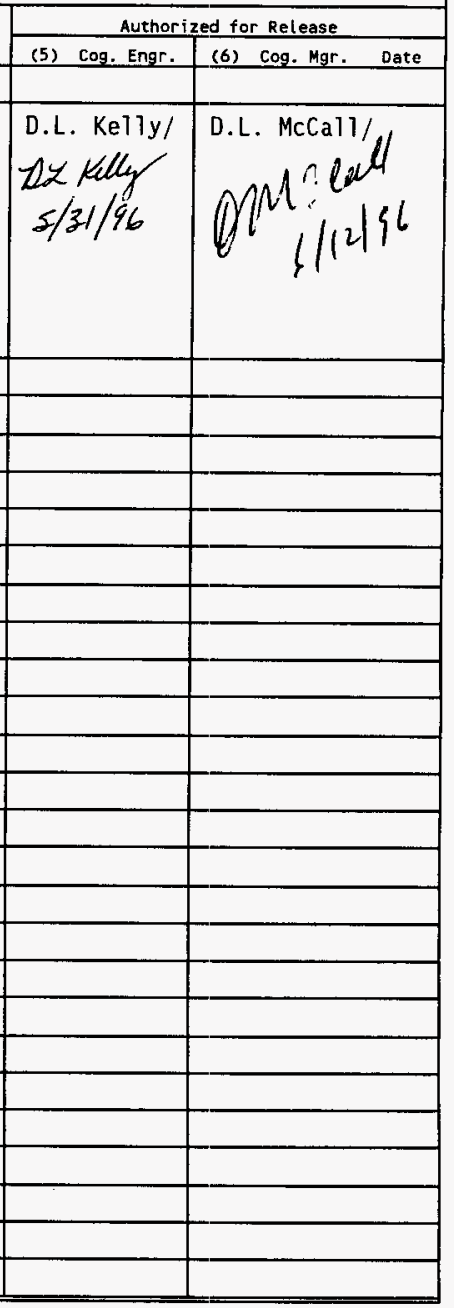


WHC-SD-TP-RPT-018

Revision 1

\section{CONTENTS}

1.0 INTRODUCTION ........................ . . . . .

1.1 PURPOSE . . . . . . . . . . . . . . . . . . . . . . . 1-1

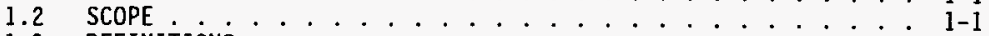

1.3 DEFINITIONS $\ldots \ldots \ldots$

1.4 MANUFACTURER-QUALIFIED PACKAGING $\ldots \ldots \ldots \ldots$

1.5 DOE-QUALIFIED PACKAGING . . . . . . . . . . . . 1-2

2.0 GENERAL TEST DESCRIPTION . . . . . . . . . ... 2-1

2.1 PRE-TEST ACTIVITIES . . . . . . . . . . $2-2$

2.1.1 Design Verification Review .......... 2-2

2.1.2 Test Plan Development ............ 2- 2-

2.1.3 Preloading Inspections ............ 2-3

2.2 PERFORMANCE REQUIREMENTS AND Closure ......... . . . 2-3

2.2.1 Reduced Pressure Test [ 49 CFR $173.412(\dot{f}) j] \ldots . .2-3$

2.2.2 Vibration Test Standard [49 CFR 178.608] . . . . . . 2-4

2.2 .3 Water Spray Test $[173.465(\mathrm{~b})] \ldots . . . . .2-4$

2.2.4 Stacking Test $[173.465(d)] \ldots 2-5$

2.2.5 Penetration Test [173.465(e) and 173.466(a)(2)] . . . 2-5

2.2.6 Free Drop Test $[173.465(\mathrm{c})$ and $173.466(\mathrm{a})(1)] \ldots . .2-5$

2.3 POST-TEST ACTIVITIES . . . . . . . . $2-7$

2.4 PASS/FAIL CRITERIA $\ldots \ldots \ldots$

2.5 TEST EXCEPTIONS . . . . . . . . . . . . . . . . . . . 2-8

2.6 TEST DATA . . . . . . . . . . . . . . . . . . $2-8$

3.0 TEST FACILITIES AND EQUIPMENT . . . . . . . . . . . . . 3-1

3.1 STANDARDS AND QUALITY OF OPERATIONS $\ldots \ldots \ldots$

3.2 TEST FACILITIES . . . . . . . . . . . . . $3_{3-1}$

3.3 EQUIPMENT REQUIRED . . . . . . . . . . . . . . . . . .

3.4 CALIBRATION AND MAINTENANCE OF EQUIPMENT $\ldots \ldots . \ldots 3-2$

4.0 PERSONNEL REQUIREMENTS ................... . . . . . .

4.1 PROJECT ENGINEER $\ldots \ldots \ldots$

4.2 TEST ENGINEER $\ldots \ldots \ldots \ldots$

4.3 SAFETY ENGINEER . . . . . . . . . . . . . . . . 4

4.4 QA ENGINEER $\ldots . \ldots \ldots$

4.5 RIGGERS AND OPERATORS $\ldots \ldots \ldots$

4.6 PHOTOGRAPHER/VIDEOGRAPHER . . . . . . . . . . . . . . 4-2

4.7 NON-DESTRUCTIVE TEST PERSONNEL . . . . . . . . . . . 4-2

5.0 ENVIRONMENT \& SAFETY . . . . . . . . . . . . . . 5-1

5.1 SAFETY BRIEFING $\ldots \ldots \ldots$

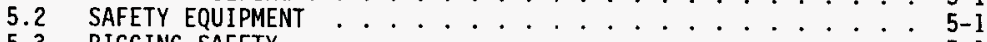

5.3 RIGGING SAFETY $\ldots \ldots \ldots \ldots \ldots \ldots$

5.4 ENVIRONMENTAL FACTORS $\ldots \ldots \ldots \ldots \ldots$ 
WHC-SD-TP-RPT-018
Revision 1

CONTENTS (cont.)

6.0 PRE-TEST PROCEDURES . . . . . . . . . . . . . . . 6-1

6.1 DESIGN VERIFICATION REVIEW .............. . . 6-1

6.2 TEST PLAN DEVELOPMENT . . . . . . . . . . . . . . . . . . $6-1$

6.3 TEST UNIT MARKING ................... . . . $6-2$

6.4 PRELOADING INSPECTIONS ................. . . . . . . . .

6.4.1 Visual Inspection.................... 6-4

6.4.2 Component Weights............... . . 6-4

6.4.3 Wa11 Thicknesses . . . . . . . . . . . . . . 6-5

6.5 ASSEMBLY, LOADING, AND CLOSURE ............... . . . $6-5$

7.0 PERFORMANCE TEST PROCEDURES . . . . . . . . . . . . . . . 7-1

7.1 REDUCED PRESSURE TEST . . . . . . . . . . . . . . . . . . 7-1

7.1.1 Initial Conditions . . . . . . . . . . . . . . . . . 7-1

7.1.2 Test - Pressure Elevation Method . . . . . . . . . . 7-2

7.1.3 Test - Pressure Reduction Method . . . . . . . . . . . 7-3

7.1.4 Post Test Condition ............. . . 7-3

7.2 VIBRATION STANDAROS TEST .............. $7-4$

7.2.1 Initial Conditions . . . . . . . . . . . . . 7-4

7.2.2 Test Procedure ................. . 7-4

7.3 WATER SPRAY TEST ....................... . . . . . . 7 .

7.3.1 Initial Conditions . . . . . . . . . . . . . . 7-5

7.3.2 Test Procedure . . . . . . . . . . . . . . . . 7-6

7.4 STACKING TEST . . . . . . . . . . . . . . . . . . . . . . . 7-7

7.4.I Initial Conditions . . . . . . . . . . . . . . 7-7

7.4.2 Test Procedure . . . . . . . . . . . . . . . 7-7

7.5 PENETRATION TEST ................... . . . . .

7.5.1 Initial Conditions . . . . . . . . . . . . . 7-8

7.5.2 Test Procedure . . . . . . . . . . . . . . 7-8

7.6 FREE DROP TEST . . . . . . . . . . . . . . . . . . . . . . $7-9$

7.6.1 Initial Conditions . . . . . . . . . . . . 7-9

7.6.2 Test Procedure . . . . . . . . . . . . . . 7-10

8.0 POST-TEST PROCEDURES . . . . . . . . . . . . . . . . . 8-1

8.1 CONTAINMENT BOUNDARY VERIFICATION . . . . . . . . . . . . $8-1$

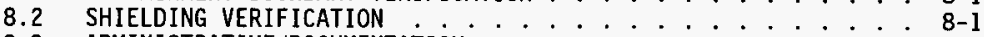

8.3 ADMINISTRATIVE/DOCUMENTATION . . . . . . . . . . . . . . . $8-1$

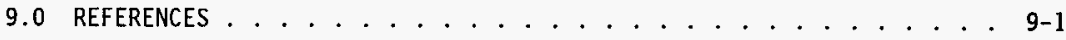

10.0 GLOSSARY . . . . . . . . . . . . . . . . . . . . GL-1

APPENDIX A HANFORD PACKAGING TEST CAPABILITIES . . . . . . . . . . . . . . A-1

APPENDIX B EXAMPLE OUTLINE - TEST PLAN . . . . . . . . . . . . . . . . . . B-1

APPENDIX $\mathrm{C}$ TEST DATA SHEETS . . . . . . . . . . . . . . . . . . . . $\mathrm{c}-1$ 


\section{WHC-SD-TP-RPT-018 \\ Revision 1}

\section{LIST OF FIGURES}

Figure 1-1. Typical Package Test Orientation Parameter - Impact Angle - 1-3 Figure 1-2. Typical Package Test Orientation Parameter - Orientation. . 1-4

Figure 6-1. Typical Package Test Unit Marking ............ . 6-3

\section{LIST OF TABLES}

Table 2-1. Free-Fall Distance By Weight . . . . . . . . . . 2-6

Table 2-2. Free-drop Distance By Packaging Material . . . . . . . . . 2-6 
WHC-SD-TP-RPT-018

Revision 1

\section{DOT-7A TYPE A PACKAgING TEST AND EVALUATION PROCEDURE}

\subsection{INTRODUCTION}

Engineering documentation associated with Westinghouse Hanford Company's (WHC) Transportation \& Packaging (T\&P) operations and activities shall be identified, prepared, reviewed, and controlled according to the requirements of WHC-CM-6-1, Standard Engineering Practices. The Engineering Practice Guides (EPG) contained in WHC-IP-1026 provide guidance (i.e., procedures, flowcharts, and tables) for completion of engineering tasks. The E.PG appendices provide format and content guidance for various types of engineering documents, including test procedures. This document follows that guidance.

\subsection{PURPOSE}

The purpose of this document is to provide guidance for qualifying a U.S. Department of Transportation Specification 7A Type A (DOT-7A) packaging for use. WHC qualifies DOT-7A packaging for two purposes. The first is to provide packages for use by WHC. The packaging qualified through this process is referred to in this document as "manufacturer-qualified." The second purpose is to provide a contracted service in support of the U.S. Department of Energy, Office of Transportation, Emergency Management, and Analytical Services (DOE/EM-76). The packaging qualified through this process is referred to as "DOE-qualified." To become DOE-qualified, an applicant must submit the packaging design to the Packaging Certification Staff (DOE/EM-76).

\subsection{SCOPE}

This test and evaluation procedure documents the steps involved in qualifying DOT-7A packages. It includes descriptions of the performance tests, the personnel involved and their qualifications, appropriate safety and quality assurance considerations, and the procedures to be followed when WHC performs the tests (either as the manufacturer, or on behalf of the DOE's certification program). Sections are referenced from Title 49 of the Code of Federa1 Regulations, "Transportation," (49 CFR) that address performance requirements applicable to DOT-7A packagings.

\subsection{DEFINITIONS}

Applicant - The applicant is the person or organization that requests DOT-7A packaging testing and evaluation be conducted. The applicant may be associated with either a DOE-qualified or manufacturer-qualified packaging. 
WHC-SD-TP-RPT-018

Revision I

Impact Angle -

The impact angle is used in drop testing to indicate the angle of the package with respect to the target at impact. The value will be the angle formed by the longest horizontal centerline axis of the package in its normal upright position as measured with respect to the horizontal plane of the impact target (see Figure 1.1).

Orientation - The orientation on a package is used to define points of impact in drop or penetration testing. The orientation may be identified by a specific feature or an angle measured from the shortest horizontal centerline axis of the package in its normal upright position as measured with respect to the horizontal plane of the impact target (see Figure 1.2).

\subsection{MANUFACTURER-QUALIFIED PACKAGING}

Manufacturer-qualified DOT-7A packagings are reviewed by WHC's T\&P organization. Individuals shall notify T\&P's Packaging Safety Engineering (PSE) group regarding the packaging design. Once an approved design has been obtained, the Packaging Operations and Development (PO\&D) group shall conduct the appropriate testing activities.

- WHC-CM-2-14, Hazardous Material Packaging and Shipping

- WHC-CM-4-2, Quality Assurance Manual

- WHC-CM-6-1, Standard Engineering Practices

- WHC-IP-1026, Engineering Practice Guidelines.

Packagings that are tested and qualified in this manner are not considered as being DOE-qualified packaging, and are not documented in DOE's Test and Evaluation Document for DOT Specification 7A Type A Packaging (Cruise 1992).

\subsection{DOE-QUALIFIED PACKAGING}

A DOE-qualified Type A packaging is tested and evaluated by a DOEapproved test facility. WHC conducts testing at the Hanford Site as a DOEapproved test facility. A docket must first be opened by the applicant. To open a docket, applicants must contact the administrative contacts identified in DOE's Test and Evaluation Document for DOT Specification 7A Type A Packaging, Section 1.1.l, "Administrative Contacts" (Cruse 1992). Contractors requesting that a packaging go through the DOE-qualification process should inform their local DOE site office that they are opening a test docket. Packagings that are approved for use by the DOE are placed into the Test and Evaluation Document. 
WHC-SD-TP-RPT-018

Revision 1

Figure 1-1. Typical Package Test Orientation Parameter - Impact Angle.

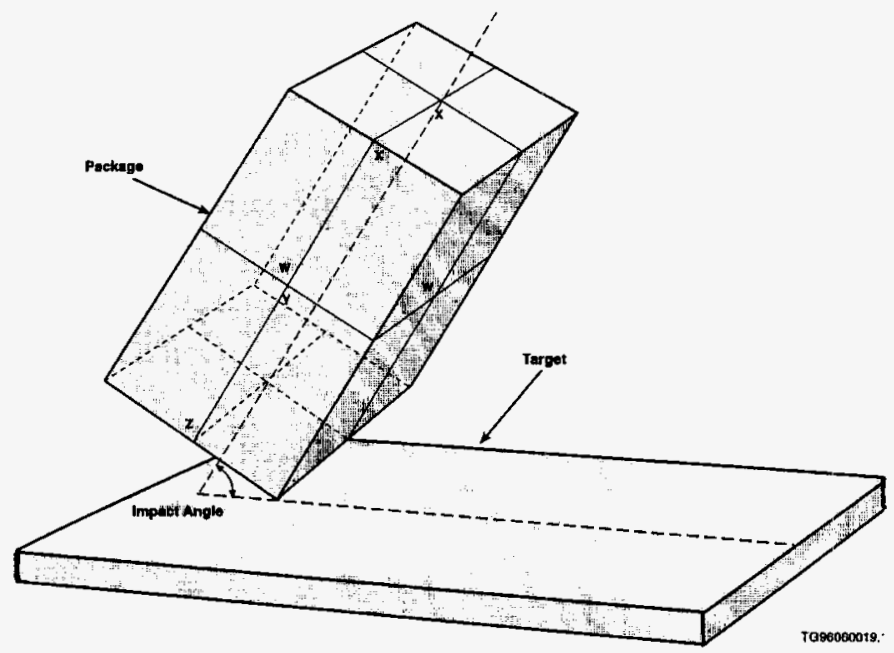


WHC-SD-TP-RPT-018

Revision 1

Figure 1-2. Typical Package Test Orientation Parameter - Orientation.

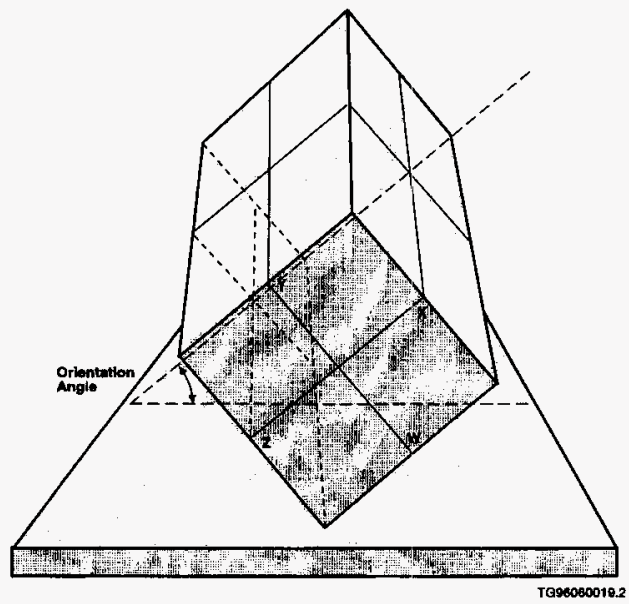


WHC-SD-TP-RPT-018

Revision 1

Appropriate WHC policies and procedures shall be followed, such as:

- WHC-CM-2-14, Hazardous Material Packaging and Shipping

- WHC-CM-4-2, Quality Assurance Manual

- WHC-CM-6-1, Standard Engineering Practices

- WHC-1P-1026, Engineering Practice Guidelines. 
WHC-SD-TP-RPT-018

Revision 1

\subsection{GENERAL TEST DESCRIPTION}

The objective of this test and evaluation procedure is to direct the verification activities used to demonstrate that a proposed packaging meets the DOT-7A Type A packaging design and construction requirements as specified by 49 CFR 178.350, Specification 7A; General Packaging, Type $A$.

The following lists the primary sections of 49 CFR applicable to a DOT-7A packaging:

NOTE: This list highlights the performance requirements and is not intended to present an al1-encompassing list.

- $\quad 173.24$

- $\quad 173.24 \mathrm{a}$

- $\quad 173.24 b$

- $\quad 173.403$

- $\quad 173.410$

$-173.412$

- $\quad 173.415(\mathrm{a})$

- $\quad 173.442$

- $\quad 173.461$

- $\quad 173.462$

- $\quad 173.463$

- $\quad 173.465$

$-173.466$

- $\quad 173.474$

- $\quad 173.475$
General Requirements for Packagings and Packages

Additional General Requirements for Non-Bulk

Packagings and Packages

Additional General Requirements for Bulk Packagings

Definitions

Genera7 Design Requirements

Additional Design Requirements for Type A Packages

Authorized Type A Packages

Thermal Limitations

Demonstration of Compliance with Tests

Preparations of Specimens for Testing

Packaging and Shielding - Testing for Integrity

Type A Packaging Tests

Additional Tests for Type A Packagings Designed for Liquids and Gases

Quality Control for Construction of Packaging

Quality Control Requirements Prior to Each Shipment of Class 7 (Radioactive) Materials 
WHC-SD-TP-RPT-018

Revision 1

- $\quad 178.3$

- $\quad 178.350$

- $\quad 178.608$
Marking of Packagings

Specification $7 \mathrm{~A}$; General Packaging, Type A

Vibration Standards

When subjected to the tests specified in 49 CFR 173.465 and 173.466, the packaging will prevent the following:

- Loss or dispersal of the radioactive contents; and

- Any significant increase in the radiation levels recorded or calculated at the external surfaces as compared to the condition before the test.

This test and evaluation procedure involves activities associated with pretest design evaluations, inspections, loading of a simulated payload, testing, and evaluation. Based on this procedure and by following a predetermined test $\mathrm{plan}$ specific to the packaging being tested, the test packages (test units) are subjected to a series of performance tests followed by post test inspections and evaluations. The sections that follow provide a general description of each of these activities.

\subsection{PRE-TEST ACTIVITIES}

\subsubsection{Design Verification Review}

The first step in qualification of a packaging is to review the data package provided by the applicant. That data should consist of a completed Packaging Qualification Checklist (PQCL), drawings, specifications, an analysis report, and operating instructions. For an example of the $P Q C L$, refer to Appendix B of the Regulatory Compliance Guide for DoT-7A Type A Packaging Design (Kelly 1995). The PO\&D Project and Test Engineers will review the supplied data and resolve any concerns with the applicant.

\subsubsection{Test Plan Development}

Upon completion of the design verification review, the P0\&D Test Engineer prepares a test pian that details all subsequent steps of preloading inspections through testing, and post test activities. The test plan will detail the test sequence, the parameters to be used for each test (including initial and pass/fail conditions), and other critical elements such as the allowable time period between tests. The determination of test sequence and parameters is based on the type of package, materials of construction, and the contents. For informational purposes, an example test plan outline is included as Appendix $B$ of this document. 
WHC-SD-TP-RPT-018

Revision 1

The test plan will detail the sequence for each test unit and will be reviewed and approved by Safety, Quality Assurance (QA), and an independent party within the T\&P organization who is knowledgeable in packaging testing. Approval signatures will be shown on the Engineering Data Transmittal (EDT) or on an Engineering Change Notice (ECN), whichever is applicable per WHC procedures. Test plans for the qualification of a Type A packaging will generally fall under the category of an operability test procedure and report. For additional information that should be considered and/or included in the preparation of the test plan to be used, refer to WHC-IP-1026, Engineering Practice Guidelines, Appendix L, "Operability Test Procedures and Reports."

\subsubsection{Preloading Inspections}

Each test unit will be inspected before testing to ensure compliance with the design and to record certain as-built features. This will, as a minimum, involve a general visual inspection, measurement of component weights, and the measurement of the containment boundary wall thickness at several locations. These inspections will be detailed in the test plan.

\subsubsection{Assembly, Loading, and Closure}

Assembly, loading, and closure of the test units will be performed in a prototypic manner and in accordance with the operating instructions provided by the applicant.

\subsection{PERFORMANCE REQUIRENENTS AND TESTS}

As required by 49 CFR $173.412(j)$, when subjected to the tests specified in 49 CFR 173.465 and 173.466, the packaging will prevent the following:

- Loss or dispersal of the radioactive contents; and

- Any significant increase in the radiation levels recorded or calculated at the external surfaces as compared to the condition before the test.

\subsubsection{Reduced Pressure Test [49 CFR 173.412(f)]}

In addition to meeting the general design requirements prescribed in 49 CFR 173.410, each Type A packaging must be designed so that the containment system will retain its radioactive contents under the reduction of ambient pressure to $25 \mathrm{kPa}(3.6 \mathrm{psi})$. The reduced pressure test is applied and is intended to simulate the reduction of ambient (external) pressure to the package to $25 \mathrm{kPa}(3.6 \mathrm{psia})$. The atmospheric pressure at the Hanford Site is typically equal to $1 \mathrm{Atm}$ ( $14.7 \mathrm{psi}$ ). Atmospheric pressure should be confirmed with the Hanford Weather Station prior to testing activities. 
WHC-SD-TP-RPT-018

Revision 1

A reduction in ambient pressure will result in a sealed package being subjected to a pressure differential equal to $78.0 \mathrm{kPa}(11.3 \mathrm{psig})$. This may be achieved by pressurizing the internal cavity of the packaging to $78.0 \mathrm{kPa}$ (11.3 psig) or by placing a closed packaging into a chamber that can be evacuated to $25 \mathrm{kPa}$ (3.6 psia). In both cases, leak detection by visual, soap bubble, pressure change, or other method is used. The method is determined by the Project and/or Test Engineer, and is reflected in the test plan for a given packaging.

Refer to Section 7.1 of this procedure for performance test procedures associated with the reduced pressure test.

\subsubsection{Vibration Test Standard [49 CFR 178.608]}

The vibration test standard is applied to Type A packages to demonstrate compliance with 49 CFR $173.410(f)$. Three sample packagings must be filled and closed as for shipment, and placed on a vibrating platform that has a vertical or rotary double-amplitude (peak-to-peak displacement) of $2.54 \mathrm{~cm}$ (1 in.).

The packages should be constrained horizontally to prevent them from falling off the platform, but must be left free to move vertically, bounce, and rotate. The test is performed for 1 hour at a frequency that causes the package to be raised from the vibrating platform such that a piece of material approximately $1.6 \mathrm{~mm}$ ( $0.063 \mathrm{in.})$ thick can be passed between the bottom of any package and the platform. Immediately following the period of vibration, each package must be removed from the platform, turned on its side, and observed for any evidence of leakage.

Refer to Section 7.2 of this procedure for performance test procedures associated with the vibration test.

\subsubsection{Water Spray Test [173.465(b)]}

The water spray test simulates exposure to rainfall of approximately $5 \mathrm{~cm}$ (2 in.) per hour for at least 1 hour. This test must precede each of the other tests or test sequences described in 49 CFR 173.465. The time interval between the end of the water spray test and the beginning of the next test shall be such that the water has soaked-in to the maximum extent without appreciable drying of the exterior of the package. A time interval of 2 hours may be used if the spray is applied from four different directions simultaneously, and there is no sign of a need for a shorter or longer soak time. Other tests will follow immediately if the spray is applied from each of the four directions consecutively. The water spray test must not have a negative effect on the performance of the packaging.

Refer to Section 7.3 of this procedure for performance test procedures associated with the water spray test. 
WHC-SD-TP-RPT-018

Revision 1

\subsubsection{Stacking Test [173.465(d)]}

The stacking test lasts for a period of at least 24 hours. The compressive load is equivalent to either five times the weight of the actual package or $13 \mathrm{kPa}\left(1.9 \mathrm{lb} / \mathrm{in}^{2}\right)$ multiplied by the vertically projected area of the package, whichever is greater. The load is applied uniformly to two opposite sides of the package, one of wich must be the base on which the package would normally stand. The stacking test must not have a negative effect on the performance of the packaging.

Refer to Section 7.4 of this procedure for performance test procedures associated with the stacking test.

\subsubsection{Penetration Test [173.465(e) and $173.466(\mathrm{a})(2)]$}

The package is placed on a rigid, flat, horizontal surface that will not move. A bar (penetration bar) $3.2 \mathrm{~cm}$ (1.25 in.) in diameter with a hemispherical end, weighing $6 \mathrm{~kg}(13.2 \mathrm{lb})$, with its longitudinal axis vertical, is dropped onto the center of the weakest part of the package, so that, if it penetrates far enough, it will hit the containment system. The bar must not be deformed by the test. There must be no loss of containment from the tested packaging, and consideration must be taken for any damage received to the tested packaging that could cause any significant increase in the radiation level at the external surface of the package.

The distance of the fall of the bar is measured from its lower end to the upper surface of the package. The determination of this distance depends on the basic physical form of the contents for which the packaging is designed. The penetration drop height for packagings designed to contain only solids is $1 \mathrm{~m}(3.3 \mathrm{ft})$. An additional penetration bar drop test is required for packagings designed to contain liquids and/or gasses. In this instance, this distance is $1.7 \mathrm{~m}(5.5 \mathrm{ft})$.

Refer to Section 7.5 of this procedure for performance test procedures associated with the penetration test.

\subsubsection{Free Drop Test [173.465(c) and 173.466(a)(1)]}

The free-fall distance depends on the weight and type of packaging material used, as well as the physical form of the material to be placed into the packaging. The free drop test consists of a fall onto a flat, horizontal, rigid surface. The orientation of the test package is such that the fall will cause maximum damage to the package and its safety features. The distance of the fall will be measured from the lowest part of the packaging to the upper surface of the target. There must be no loss of containment from the tested packaging, and consideration must be taken for any damage received to the tested packaging that could cause any significant increase in the radiation level at the external surface of the package. 
WHC-SD-TP-RPT-018

Revision 1

Packagings having a particular mass will undergo the free drop test at the applicable drop distance shown in Table 2-1. Packagings designed for liquids and gasses shall be capable of withstanding an additional free drop test from a distance not less than $9 \mathrm{~m}(30 \mathrm{ft})$.

Table 2-1. Free-Fall Distance By Weight.

\begin{tabular}{|c|c|c|c|}
\hline \multicolumn{2}{|c|}{ Packaging Weight } & \multicolumn{2}{c|}{ Free-drop Distance } \\
\hline Kilograms & Pounds & Meters & Feet \\
\hline$\leq 5,000$ & $\leq 11,000$ & 1.2 & 4 \\
\hline$>5,000$ to 10,000 & $>11,000$ to 22,000 & 0.9 & 3 \\
\hline$>10,000$ to 15,000 & $>22,000$ to 33,000 & 0.6 & 2 \\
\hline$>15,000$ & $>33,000$ & 0.3 & 1 \\
\hline
\end{tabular}

Additional drop tests are required based on materials of construction as shown in Table 2-2.

Table 2-2. Free-drop Distance By Packaging Material.

\begin{tabular}{||l|l|l|l|}
\hline Packaging Material & $\begin{array}{l}\text { Packaging } \\
\text { Weight }\end{array}$ & $\begin{array}{l}\text { Free- } \\
\text { Drop } \\
\text { Distance }\end{array}$ & Free-Drop Orientation \\
\hline $\begin{array}{l}\text { Fiberboard or wood } \\
\text { rectangular packaging }\end{array}$ & $\begin{array}{l}\leq 50 \mathrm{~kg} \\
(\leq 110 \mathrm{jb})\end{array}$ & $\begin{array}{l}0.3 \mathrm{~m} \\
(1 \mathrm{ft})\end{array}$ & Onto each corner \\
\hline $\begin{array}{l}\text { Fiberboard cylindrical } \\
\text { packaging }\end{array}$ & $\leq 100 \mathrm{~kg}$ \\
$(\leq 220 \mathrm{jb})$ & $\begin{array}{l}0.3 \mathrm{~m} \\
(\mathrm{l} \mathrm{ft})\end{array}$ & $\begin{array}{l}\text { Onto each of the } \\
\text { quarters of each rim }\end{array}$ \\
\hline
\end{tabular}

For packages containing fissile material, the free drop test specified in 49 CFR 173.465 (c) (1) must be preceded by a free drop from a height of $0.3 \mathrm{~m}$ $(1 \mathrm{ft}$ ) on each corner, or in the case of cylindrical packages, onto each of the quarters of each rim.

Refer to Section 7.6 of this procedure for performance test procedures associated with the drop test. 
WHC-SD-TP-RPT-018

Revision 1

\subsubsection{Drop Test Pad Requirements}

Per 49 CFR 173.465 (c) (5), the target for the free drop test must be a flat, horizontal surface of such mass and rigidity that any increase in its resistance to displacement or deformation upon impact by the specimen would not significantly increase the damage to the specimen.

The International Atomic Energy Agency's Safety Series No. 37, "Advisory Material for the IAEA Regulations for the Safe Transport of Radioactive Material" (IAEA 1990), provides the following recommendation for a test pad:

A-618. One example of an unyielding target to meet the regulatory requirements is a steel plate as the upper surface of a concrete block. The combined mass of the steel and concrete should be at least 10 times that of the specimen to be dropped on it. The block should be set on firm soil and the steel plate should be at least $4.0 \mathrm{~cm}(1.57$ in.) thick and floated onto the concrete while it is still wet. The plate would have protruding fixed steel structures on its lower surface to ensure tight contact with the concrete. Since flexure of the target is to be avoided, especially in the vertical direction, it is recommended that the target should be close to cubic in form, with the depth of the target comparable to the width and length.

\subsection{POST-TEST ACTIVITIES}

Following completion of each individual performance test, the test units will be inspected for damage and assessed for adequacy. Upon completion of all of the tests, the Test Engineer will prepare a test report (final evaluation report) according to the guidelines set forth in WHC-CM-6-1, Standard Engineering Practices, and WHC-IP-1026, Engineering Practice Guidelines, Appendix L, "Operability Test Procedures and Reports." The final evaluation report, whether for a manufacturer-qualified or a DOE-qualified packaging, will receive review and approval from Safety, QA, and an independent party within the T\&P organization who is knowledgeable in DOT-7A packaging requirements. Additionally, if the packaging is to be DOEqualified, the final evaluation report will be submitted to DOE/EM-76 for review and approval.

\subsection{PASS/FAIL CRITERIA}

The package(s) must perform adequately when subjected to the applicable performance tests which are described in Section 2.2 of this document. There should be evidence that the integrity of the packaging would remain with no significant release of the hazardous materials to the environment ( 49 CFR 173.24), no loss or dispersal of radioactive contents, and no significant increase in the radiation levels recorded or calculated at the external surfaces for the condition before the test [49 CFR $173.412(j)]$. 
WHC-SD-TP-RPT-018

Revision 1

For testing purposes, "significant increase in the radiation levels," means more than a 20 percent increase in the radiation level at any external surface of the package (IAEA 1985).

Because any radiation level increase would be dependent on the radioactive package contents, this criterion must be evaluated for specific package contents whenever damage to the packaging occurs as a result of the test conducted. Documentation of any decrease in effectiveness of the shielding, in a way that will enable a determination of acceptability be made by any package user for any contents, will be incorporated into the final evaluation report.

\subsection{TEST EXCEPTIONS}

This test procedure or its sequence may be altered by approval of the Project Engineer or Test Engineer. The Safety Engineer will approve safetyrelated changes as determined by the Project Engineer; the QA Engineer wi11 approve quality-related changes as determined by the Project Engineer.

Significant changes to DOE-qualified packagings will be evaluated and approved by the Packaging Certification Staff (DOE/EM-76), as determined by the Project Engineer. Significant changes to manufacturer-qualified packagings will be evaluated and approved by $T \& P$, as determined by the Project Engineer.

\subsection{TEST DATA}

Data collected during evaluation and testing shall consist of a completed PQCL and the test data sheets as invoked by Sections $6.0,7.0$ and 8.0 of this document, still-photos and/or video tape records, drawings, and reports from non-destructive testing (NDT) as needed. Analys is of data shall be presented in a final evaluation report upon completion of testing. All original data and documentation shall be referenced and maintained according to WHC-CM-6-1, Standard Engineering Practices. 
WHC-SD-TP-RPT-018

Revision 1

\subsection{TEST FACILITIES AND EQUIPNENT}

\subsection{STANDARDS AND QUALITY OF OPERATIONS}

A DOE-certified test facility must conduct packaging testing and evaluation operations in accordance with DOE guidance and appropriate quality standards. WHC conducts testing at the Hanford Site as a DOE-approved test facility.

Packagings may also be manufacturer-qualified. In this case, testing will be conducted, and documentation will be obtained and maintained according to the information and procedures described in this document.

\subsection{TEST FACILITIES}

A complete discussion of the Hanford Site packaging test capabilities, including the test facilities, is included as Appendix $A$ of this document.

Packaging test facilities at the Hanford Site include the 305 Building that houses a small, indoor drop pad, penetration, water spray, leakage rate, and other test equipment. The 305 Building drop test pad can accommodate packages that weigh up to $1179 \mathrm{~kg}(2600 \mathrm{lb})$, and measure up to $183 \mathrm{~cm}$ by 152 $\mathrm{cm}$ (72 in. by $60 \mathrm{in.}$.). Non-destructive testing (NDT) may be performed by the trained and certified staff located at the 306E Building.

Two outdoor drop pads are used for drop testing larger packages. Packages that weigh up to $11,793 \mathrm{~kg}(26,000 \mathrm{lb})$, and measure up to $244 \mathrm{~cm}$ by $122 \mathrm{~cm}$ (96 in. by 48 in.) may be accommodated by the 300 Area test pad.

\subsection{EQUIPMENT REQUIRED}

Special tools, measuring devices, movable equipment, and supplies are required to perform testing activities. The specific items needed for a test should be identified in the test plan, and include the following:

- Calibrated weighing devices

- Weights for stacking test

- Penetration bar

- Vibration table

- Hoisting and rigging equipment for free drops

- Quick release mechanism

- Overhead or mobile crane

- Dimensional and leakage rate measuring equipment, as needed

- Calibrated pressure measuring devices

- Pneumatic pressure test equipment

- Hydrostatic pressure test equipment

- Water spray conditioning system 
WHC-SD-TP-RPT-0:18

Revision 1

- Water tank, if needed

- Necessary safety equipment (refer to Section 5.2 of this document)

- Camera and/or video equipment.

A complete discussion of the equipment used at the Hanford Site is included as Appendix $A$ of this document.

\subsection{CALIBRATION AND MAINTENANCE OF EQUIPMENT}

Verification of all instrument and weight calibration shall be performed prior to use in testing.

The WHC QA program (see WHC-CM-4-2, Quality Assurance Manual) has established requirements for the control of instruments applicable to measuring and test equipment, calibrated plant-installed instrumentation, and laboratory instruments (QR 12.0, "Control of Instruments," and QI 12.4, "Calibration Control of Measuring and Test Equipment"). These control requirements are not necessary for rulers, tape measures, levels, analytical glassware, and other fixed measurement devices if commercial equipment provides accuracy adequate to meet the measurement specifications.

The Standards Laboratory is responsible for preparing the administrative procedures that define and describe a measuring and test equipment control system. All measuring and test equipment are uniquely identified, and an inventory of instruments and their location has been developed and is kept current. Instruments are calibrated following approved procedures or instructions. The manufacturer's calibration instructions or nationally recognized standard practices and methods may be used. If no recognized standard exists, the basis for calibration is documented. Calibration procedures or the appropriate controlling work document shall be used. offsite calibration services shall be performed in accordance with QR 7.0, "Control of Purchased Items and Services."

Chronological records documenting the calibration history of each instrument are maintained to provide evidence that the instrument was used while in-calibration or in-control. Each record identifies the instrument to which it applies, the procedure or instruction followed in performing the calibration, the calibration data, the identity of the standard used, the identity of the person performing the calibration, and the calibration date.

Standards, including appropriate measuring and test equipment, used for calibrating instruments have the range, precision, and accuracy required to maintain the instruments within their required tolerances. Instruments are calibrated at appropriate intervals to verify the required accuracy.

Nonconforming instruments are identified to prevent inadvertent use. Nonconforming instruments shall not be used until repairs and adjustments have been made to restore accuracy and satisfactory calibration is obtained. 
WHC-SD-TP-RPT-018

Revision 1

\subsection{PERSONNEL REQUIREMENTS}

\subsection{PROJECT ENGINEER}

The Project Engineer has overall responsibility for the cost, schedule, testing, and evaluation activities performed by WHC under the DOE-sponsored Type A Program, or on-site Type A program testing. The Project Engineer shall be fully qualified by experience and/or formal training to perform assigned engineering and testing tasks. The Project Engineer shall receive all necessary DOT regulatory training as identified by 49 CFR 172.700. Training records are documented, reviewed, and maintained per WHC-CM-2-15, Training Standards.

\subsection{TEST ENGINEER}

The Test Engineer is responsible for directing all related testing and evaluation activities and assuring the quality, safety, and validity of the test sequences. In addition, the Test Engineer is responsible for presenting the documented results in a final test report. The Test Engineer shall be fully qualified by experience and/or training to perform assigned testing tasks. The Test Engineer shall receive all necessary DOT regulatory training as identified by 49 CFR 172.700 . Training records are documented, reviewed, and maintained per WHC-CM-2-15, Training Standards.

\subsection{SAFETY ENGINEER}

The Safety Engineer is an independent Industrial Health and Safety representative responsible for verifying compliance of the testing with all appropriate Hanford safety manuals. The Safety Engineer performs job functions within the guidelines established by WHC-CM-1-10, Safety Manual. Training records are documented, reviewed, and maintained per WHC-CM-2-15, Training Standards.

\subsection{QA ENGINEER}

The QA Engineer is an independent quality assurance representative responsible for verifying compliance of the testing with all appropriate Hanford quality assurance manuals. The QA Engineer performs job functions within the guidelines established by WHC-CM-4-2, Quality Assurance Manual. Training records are documented, reviewed, and maintained per $\mathrm{WHC}-\mathrm{CM}-2-15$, Training Standards. 
WHC-SD-TP-RPT-018

Revision 1

\subsection{RIGGERS AND OPERATORS}

Qualified lifting equipment operators shall perform the drop tests of the packages in accordance with DOE/RL 92-36, Hanford Hoisting and Rigging Manual. The manager responsible for hoisting and rigging operations shall designate a person in charge of the hoisting and rigging activities.

Qual ified operators within the Engineering Testing Laboratory shall perform the drop tests when the indoor drop test pad located in the 305 Building is used. Qualified operators within Crane \& Rigging Services shall perform the drop tests when an outdoor drop test pad is used. For information regarding drop test pad limitations at the Hanford Site, refer to Section 3.2 of this procedure.

\subsection{PHOTOGRAPHER/VIDEOGRAPHER}

When needed, a photographer and/or videographer shall be present during testing to provide recorded visual documentation of the test results.

\subsection{NON-DESTRUCTIVE TEST PERSONNEL}

When NDT is required, certified non-destructive testing personnel shall be used. Evidence of certification shall be required per WHC procedures. 
WHC-SD-TP-RPT-018

Revision 1

\subsection{ENVIRONMENT \& SAFETY}

\subsection{SAFETY BRIEFING}

All personnel directly involved with testing shall attend a safety briefing given by the Test Engineer and/or the Safety Engineer to ensure that all personnel understand the testing, their responsibilities, and the hazards involved with the testing.

During drop or other impact testing, personnel shall be excluded from the impact area to the extent to be clear of any fragments which could result from the impact. As a minimum, this distance shall be $15 \mathrm{~m}$ (50 ft) for a $9 \mathrm{~m}$ $(30 \mathrm{ft})$ free-drop test; $9 \mathrm{~m}(30 \mathrm{ft})$ for a $1.2 \mathrm{~m}(4 \mathrm{ft})$ free-drop test; and $6 \mathrm{~m}$ (20 ft) for a penetration test.

\subsection{SAFETY EQUIPMENT}

All personnel shall wear appropriate personal safety equipment as dictated by the particular test being performed and suggested by the Safety Engineer. For safety and testing integrity reasons, barricades shall be erected around the test area(s) to restrict interference from personnel not involved with the test being conducted (i.e., during the stacking test and free-drop test).

\subsection{RIGGING SAFETY}

All rigging shall be verified for current inspection, tagging and compliance with DOE/RL 92-36, Hanford Hoisting and Rigging Manual. Preventative maintenance on the crane shall be current. Prior to each 1 ift, the integrity of the hoisting and rigging equipment must be verified to provide a high degree of safety for personnel and equipment.

\subsection{ENVIRONMENTAL FACTORS}

Testing shall not be conducted in weather conditions that could affect the safety of the test personnel and/or test quality. In the case of inclement weather, the decision to postpone the testing shall be made by the Test Engineer and the Safety Engineer. 
WHC-SD-TP-RPT-018

Revision 1

\subsection{PRE-TEST PROCEDURES}

\subsection{DESIGN VERIFICATION REVIEW}

Whether the packaging is intended to be manufacturer-qualified or DOEqualified, the process for qualification of a Type A packaging will involve the applicant completing the Packaging Qualification Checki ist (PQCL) per the guidance of WHC-SD-TP-RPT-017, "Regulatory Compliance Guide for D0T-7A Type A Packaging Design," and submitting a document package to PO\&D for review. The first step in the evaluation and testing sequence will be a thorough review of the PQCL and the accompanying data by the Project and Test Engineers. This review is accomplished by performing the following:

1. Review the $P Q C L$ and the accompanying documents for compliance to the applicable regulatory requirements. Resolve any concerns or comments with the applicant.

2. Upon completion of the review and incorporation of the resolutions to any comments, the Project and/or Test Engineer will sign-off on the completion block on the PQCL.

3. Retain the completed PQCL, and include applicable information into the test report (final evaluation report).

\subsection{TEST PLAN DEVELOPMENT}

The test plan shall be developed following the design verification review. The test plan will describe the packaging configuration(s) to be tested; detail the preloading inspections to be performed; identify the simulated payload to be used; and describe the processes for preparing the test units for testing, the tests conducted and their sequence, and post test inspections. The sequences will be based on the packaging type, its intended contents, the applicable regulatory requirements and other items. Refer to WHC-CM-6-1, Standard Engineering Practices, and WHC-IP-1026, Engineering Practice Guidelines, Appendix L, "Operability Test Procedures and Reports," for further guidance in test plan development. The DOT-7A Type A test plan for a packaging may be prepared in accordance with the following steps:

1. A generic test plan outline is included in this procedure document as Appendix B. It may be used as a model in developing the specific packaging test plan.

2. Determine and state the preloading inspections, including shielding verifications, to be performed on each test unit along with the acceptance criteria. As a minimum, include a general visual inspection, measurement of component weights, and the measurement of the containment boundary wall thickness at several locations. These inspections shall al so include any preloading 
WHC-SD-TP-RPT-018

Revision 1

inspections specified in the operating instructions provided by the applicant.

3. Determine and state the simulated payload to be used for each test unit and for the specific tests it must be used.

4. Determine and state any special steps to be performed involving assembly, loading, and closure of the package for each test unit prior to testing. Normally, the test plan will merely refer to those steps included in the operating instructions provided by the applicant.

5. Determine and state the sequence and key parameters of the performance tests to be performed referencing the applicable section of this test procedure for the details of each test.

6. Determine and state any post test inspections, including shielding verification, to be performed after completion of all of the performance tests.

7. Review and sign the completed test plan. Obtain the required review and approvals from Safety, QA, and an independent party within the T\&P organization.

\subsection{TEST UNIT MARKING}

Each test unit shall be marked in accordance with the steps 1isted below. The markings shall be visible and shall not interfere with the packaging performance nor affect the visibility of key packaging features which may distort during impact testing.

1. Mark the exterior, assembled surface with four 1 ines, $90^{\circ}$ apart. Label the lines "W", "X", "Y" and "Z". See Figure 6-1 for an example. Orientation angles for drop test or penetration test impact locations will be measured from the shortest horizontal centerline axis of the package in its normal upright position.

2. If the package is being tested for DOE-qualification, mark the exterior surface of each major component with a marking that consists of the sequential integer portion of the docket number, followed by a test unit designation (i.e., the first test unit of docket 91-24-7A, would be marked "24-TU-01"; the second unit would be marked "24-TU-02"). All tests shall be identified with a number consisting of the test unit designation followed by a sequential integer indicating the test "event" as shown on the test plan (i.e., the first test on test unit 24-TU-0l would be numbered "24-TU-01-1"; the second test "24-TU-01-2", and so on). 
WHC-SD-TP-RPT-018
Revision 1

Figure 6-1. Typical Package Test Unit Marking.

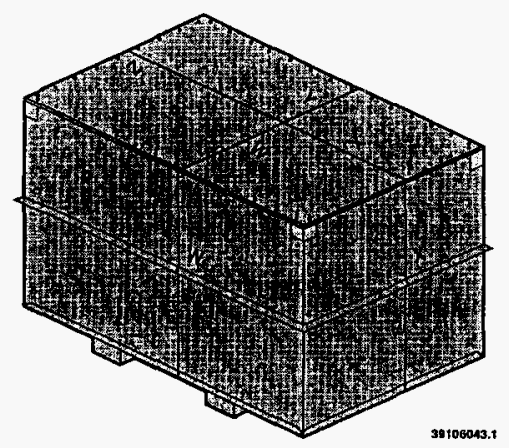


WHC-SD-TP-RPT-018

Revision 1

3. If the package is being tested for manufacturer-qualification, mark the exterior surface of each major component with a marking that will be unique for that packaging test, followed by a test unit designation (i.e., the first test unit of a particular packaging may be marked "SS-TU-01"; the second unit would be marked "SS-TU-02"). A11 tests shail be identified with a number consisting of the test unit designation followed by a sequential integer indicating the test "event" as shown on the test plan (i.e., the first test on test unit SS-TU-01 would be numbered "SS-TU-01-1"; the second test "SS-TU-01-2", and so on).

\subsection{PRELOADING INSPECTIONS}

Preloading inspections shall be performed on each test unit as invoked by the test plan. These will include the minimum inspections discussed in Section 6.2 of this document, and the inspections stated in the operating instructions provided by the applicant. The following subsections provide details on some of the inspections to be performed. Any inspections to be performed where details are not included in this procedure must be detailed in the test plan for a given packaging.

\subsubsection{Visual Inspection}

1. Visually inspect all packaging components to ensure that they are in good condition. Note specifically any of the following conditions:

- Divergence from the specifications or drawings

- Defects in construction

- Corrosion or other deterioration

- Distortion of features.

2. Note any discrepant conditions and their disposition on Test Data Sheet 6.4.1, Packaging Visual Inspections (refer to Appendix $C$ of this document). Use a separate test data sheet for each test unit.

\subsubsection{Component Weights}

1. Measure the weight of all major packaging components (i.e., lid, body, etc.).

2. Measure the weight (net/tare) of the assembled and closed packaging without simulated contents.

3. Measure the weight (gross) of the package loaded with simulated contents. 
WHC-SD-TP-RPT-018

Revision 1

4. Record the weight data on Test Data Sheet 6.4.2, Packaging Component Weights (refer to Appendix $C$ of this document). Use a separate test data sheet for each test unit.

\subsubsection{Wall Thicknesses}

1. Measure the wall thickness of the materials forming the containment boundary at several places as stated in the test plan.

2. Record the locations and measurement results on Test Data Sheet 6.4.3, Packaging Component Wall Thickness (refer to Appendix $\mathrm{C}$ of this document). Use a separate test data sheet for each test unit.

\subsection{ASSEMBLY, LOADING, AND CLOSURE}

The following steps shall be performed to complete the package preparation for testing:

1. Assemble the packaging components of each test unit per the applicant-provided operating instructions and any special steps indicated in the test plan.

2. Load the simulated payload (if applicable) per the operating instructions and any special steps indicated in the test plan.

3. Close the packaging per the operating instructions and any special steps indicated in the test plan. 
WHC-SD-TP-RPT-018

Revision 1

\subsection{PERFORMANCE TEST PROCEDURES}

The following sections provide the step-by-step details for conducting each of the performance tests. These procedures will be invoked by the test plan for a given test unit on an as-needed basis.

During most tests, a fluorescent dye (i.e., fluorescein) will be used inside test units as a leak detection medium. An ultra-violet (UV) light will be used for ease of leak detection. For greater ease in leak detection, a water mist/spray may be used in conjunction with the UV 1ight, if there will be no negative effect on the performance of the packaging. For some packagings, a different method of leak detection may be applied. The method used will be determined by the Project and/or Test Engineer, and will be based on the packaging design and contents.

\subsection{REDUCED PRESSURE TEST}

The reduced pressure test simulates the reduction of ambient (external) pressure to the package to $25 \mathrm{kPa}$ (3.6 psia) as required by 49 CFR 173.412(f). The atmospheric pressure at the Hanford Site is typically equal to 1 Atm (14.7 psi). Atmospheric pressure should be confirmed with the Hanford Weather Station prior to conducting this test.

The objective of this test is to create a pressure differential to equal a minimum of $78.0 \mathrm{kPa}$ (11.3 psig). This may be achieved by pressurizing the internal cavity of the packaging to $78.0 \mathrm{kPa}$ (11.3 psig) ("Pressure Elevation Method") or by placing an empty but closed packaging into a chamber that can be evacuated to $25 \mathrm{kPa}$ (3.6 psia) ("Pressure Reduction Method"). In both cases, leak detection by visual, soap bubble, pressure change, or other method sensitive to $10 \mathrm{E}^{-03}$ std-cc/sec will typically be used. The method is determined by the Project and/or Test Engineer, and is reflected in the test plan for a given packaging. The following subsections provide details for both methods. Note that some packages may not be designed to hold pressure. In this case, the Project and/or Test Engineer will determine an acceptable test method based on the packaging design and intended mode.

\subsubsection{Initial Conditions}

The following initial conditions shall be established prior to the test:

1. The packaging has been marked, inspected, and assembled per applicable portions of Section 6.0 of this procedure, and as invoked by the test plan. 
WHC-SD-TP-RPT-018

Revision 1

2. The atmospheric pressure at the Hanford Site is typically equal to $1 \mathrm{Atm}$ (14.7 psi). Atmospheric pressure should be confirmed with the Hanford Weather Station prior to conducting any pressure testing.

\subsubsection{Test - Pressure Elevation Method}

This procedure simulates the reduced ambient pressure conditions by elevating the pressure of the payload cavity of the packaging. Complete the following steps recording aTl data and observations. Indicate completion of steps on Test Data Sheet 7.1.2, Reduced Pressure Test (refer to Appendix C of this document). Use a separate test data sheet for each test unit.

1. Install a fitting into the containment boundary shell at a noncritical location to allow for pressurizing the payload cavity.

2. Close the packaging per the applicant's operating instructions and any special steps indicated in the test plan. Special contents or objects may be loaded into the payload cavity in order to displace the volume and limit the potential energy inside the packaging for safety reasons.

3. Pressurize the payload cavity by following one of the leak detection procedures identified in the American National 7 Standard for Radioactive Materials--Leakage Tests on Packages for Shipment (ANSI 1987).

4. Conduct the leak test in accordance with the chosen procedure. Watch for any sign of loss of simulated load.

5. At the completion of the test, record the final time, pressure, and temperature.

6. Slowly open the cut-out valve and relieve the payload cavity pressure. Secure the test equipment.

7. Evaluate the data collected during the test. Indicate a leakage rate as zero if below $1.0 \mathrm{E}^{-03} \mathrm{std}-\mathrm{cc} / \mathrm{sec}$ and "pass" if this is the case. If loss of simulated load or a detectable leakage occurs (i.e., above 1.0 $\mathrm{E}^{-03} \mathrm{std}-\mathrm{cc} / \mathrm{sec}$ ), indicate "fail." Record the results of this effort on the appropriate test data sheet.

8. Remove the package from the test set-up and prepare it for subsequent testing as indicated in the test plan. 
WHC-SD-TP-RPT-018

Revision 1

\subsubsection{Test - Pressure Reduction Method}

This procedure simulates the reduced ambient pressure conditions by reducing the external pressure to the packaging. Complete the following steps recording all data and observations. Indicate completion of steps on Test Data Sheet 7.1.3, Reduced Pressure Test (refer to Appendix C of this document). Use a separate test data sheet for each test unit.

1. If needed, install a fitting into the containment boundary shell at a non-critical location to allow for sensing pressure in the payload cavity.

2. Close the packaging per the applicant's operating instructions and any special steps indicated in the test plan. Special contents or objects may be loaded into the payload cavity in order to displace the volume and limit the potential energy inside the packaging for safety reasons.

3. Follow one of the leak test detection procedures identified in the American National Standard for Radioactive Materials--Leakage Tests on Packages for Shipment (ANSI 1987). Place the closed package in a chamber and reduce the ambient pressure to $25 \mathrm{kPa}$ (3.6 psia). Note: A lower pressure may be required to produce a pressure differential equal to $78.0 \mathrm{kPa}$ (11.3 $\mathrm{psig})$.

4. Watch for any sign of loss of simulated load.

5. At the completion of the test, record the final time, pressure and temperature.

6. Relieve the vacuum and secure the test equipment.

7. Evaluate the data collected during the test. Indicate a leakage rate as zero if below $1.0 E^{-03}$ std-c.c/sec and "pass" if this is the case. If loss of simulated load or a detectable leakage occurs (i.e., above $1.0 \mathrm{E}^{-03} \mathrm{std}-\mathrm{cc} / \mathrm{sec}$ ), indicate "fail." Record the results of this effort on the appropriate test data sheet.

8. Remove the package from the test set-up and prepare it for subsequent testing as indicated in the test plan.

\subsubsection{Post Test Condition}

In addition to determining if the reduced pressure resulted in any loss of containment, examine the package for any indication that the package was damaged in a manner that could result in a loss of shielding. Look for conditions such as movement of the load or shielding that could result in an increase in the radiation level at the surface of the package. Any change that could result in an increase of 20 percent or more over the pretest 
WHC-SD-TP-RPT-018

Revision I

condition must be evaluated for significance. If significant, the test should be marked as "failed."

\subsection{VIBRATION STANDARDS TEST}

The vibration test standard ( 49 CFR 178.608) is applied to Ty'pe A packages to demonstrate compliance with 49 CFF 173.410(f). Testing is conducted to ensure that the packaging is able to withstand the effects of any acceleration, vibration, or vibration resonance that may arise during normal transportation, without any deterioration of the effectiveness of closing devices or of the integrity of the package as a whole and without loosening or unintentional release of nuts, bolts, or other securing devices even after repeated use.

Complete the following steps recording all data and observations. Indicate completion of steps on Test Data Sheet 7.2, Vibration Test (refer to Appendix $C$ of this document). Use a separate test data sheet for each test unit.

\subsubsection{Initial Conditions}

The following initial conditions shall be established prior to the test:

1. The packaging has been marked, inspected, assembled, and closed (with payload) per applicable portions of Section 6.0 of this document, and as invoked by the test plan.

\subsubsection{Test Procedure}

1. Select three sample packagings at random.

2. Place packagings, either all three at once, or one-at-a-time, on a vibrating platform that has a vertical or rotary double-amplitude (peak-to-peak displacement) of $2.54 \mathrm{~cm}$ ( $1 \mathrm{in.)}$. The packages should be constrained horizontally to prevent them from falling off the platform, but must be left free to move vertically, bounce, and rotate.

3. Photograph or videotape the set-up condition.

4. The test is performed for 1 hour at a frequency that causes the package to be raised from the vibrating platform such that a piece of material approximately $1.6 \mathrm{~mm}(0.063 \mathrm{in}$.) thickness (such as steel strapping or paperboard) can be passed between the bottom of any package and the platform.

5. Note the start time on the appropriate test data sheet. 
WHC-SD-TP-RPT-018

Revision 1

6. Note the finish time on the appropriate test data sheet.

7. Immediately following the period of vibration, remove each package from the vibrating platform, turn the package on its side, and observe for any evidence of leakage.

8. Examine the package for conditions that could result in the surface dose rate increasing more than 20 percent. Look for conditions such as compacted load or shifting or failure of shielding. Evaluate any increase of 20 percent or greater for significance. If the change is significant, mark the test as "failed."

9. If no rupture, leakage, deterioration that could adversely affect transportation safety, or any distortion 7 iable to reduce packaging strength should result from any of the packages, indicate "pass"; otherwise indicate "fail" and explain.

10. Record the observations and results (pass or fail) on the appropriate test data sheet.

11. Photograph and/or videotape the packaging condition after the test.

12. Prepare the package for subsequent testing as indicated in the test plan.

\subsection{WATER SPRAY TEST}

The water spray test simulates exposure to rainfall of approximately $2.54 \mathrm{~cm}$ ( 2 in.) per hour for at least 1 hour.

Complete the following steps recording all data and observations. Indicate completion of steps on Test Data Sheet 7.3, Water Spray Test (refer to Appendix $C$ of this document). Use a separate test data sheet for each test unit.

\subsubsection{Initial Conditions}

The following initial conditions shall be established prior to the test:

1. The packaging has been marked, inspected, assembled, and closed (with or without payload) per applicable portions of Section 6.0 of this document, and as invoked by the test plan.

2. The water spray test must precede each test or test sequence that follows per 49 CFR 173.465 (b). 


$$
\text { WHC-SD-TP-RPT-018 }
$$

Revision 1

\subsubsection{Test Procedure}

NOTE: The time interval between the end of the water spray test and the beginning of the next test must be such that the water has soaked-in to the maximum extent without appreciable drying of the exterior of the specimen. In the absence of evidence to the contrary, this interval may be assumed to be 2 hours if the water spray is applied from four different directions simultaneously. However, no time interval may elapse if the water spray is applied from each of the four directions consecutively.

1. Set-up the necessary water spray equipment around the test unit(s). Photograph set-up.

2. Start the water spray, simulating the conditions as required [49 CFR 173.465(b)]. Record the start time and maintain the conditions for at least 1 hour.

3. Observe the package for any degradation of features during the test interval. Photograph the assembly during this time period.

4. At the completion of the minimum time interval, record the stop time, and secure the water spray equipment.

5. Examine the package for conditions that could result in the surface dose rate increasing more than 20 percent. Look for conditions such as in leakage of water, any degradation/failure of the packaging, including shielding. Evaluate any increase of 20 percent or greater for significance. If the change is significant, mark the test as "failed."

6. Note any degradation of features or other affects on the package on the appropriate test data sheet. If no degradation to the package's effectiveness occurred, indicate "pass"; otherwise indicate "fail" and explain.

7. Photograph the packaging condition after the test.

8. Remove the package from the test stand and prepare it for subsequent testing as indicated in the test plan.

9. Let the package sit for the appropriate soak time before conducting the next test. 


\section{WHC-SD-TP-RPT-C18 \\ Revision 1}

\subsection{STACKING TEST}

The stacking test lasts for a period of at least 24 hours. The compressive load is equivalent to either five times the weight of the actual package or $13 \mathrm{kPa}\left(1.9 \mathrm{lb} / \mathrm{in}^{2}\right)$ multiplied by the vertically projected area of the package, whichever is greater. The load is applied uniformly to two opposite sides of the package, one of which must be the base on which the package would normally stand.

Complete the following steps recording all data and observations. Indicate completion of steps on Test Data Sheet 7.4, Stacking Test (refer to Appendix $C$ of this document). Use a separate test data sheet for each test unit.

\subsubsection{Initial Conditions}

The following initial conditions shall be established prior to the test:

1. The packaging has been marked, inspected, assembled, and closed (with payload) per applicable portions of Section 6.0 of this document, and as invoked by the test plan.

2. Conduct the water spray test prior to conducting this test.

\subsubsection{Test Procedure}

1. The compressive load has been determined as part of the test plan development. Indicate the load to be applied on the appropriate test data sheet.

2. Assemble the necessary test weights.

3. Place the compressive load onto the package and record the initial "start" time. Photograph the loaded set-up.

4. Hold the test conditions for a mirimum of 24 hours. Observe and photograph.

5. After at least 24 hours, record the time and remove the weights from the package test set-up.

6. Examine the package for conditions that could result in the surface dose rate increasing more than 20 percent. Lock for conditions such as compacted load or shifting or failure of shielding. Evaluate any increase of 20 percent or greater for significance. If the change is significant, mark the test as "failed." 
WHC-SD-TP-RPT-018

Revision 1

7. Note any degradation of features or other affects on the package on the appropriate test data sheet. If no degradation to the package's effectiveness occurred, indicate "pass"; otherwise indicate "fail" and explain.

8. Photograph the appearance of the tested package, and any degradation of features.

9. Remove the package from the stacking test area and prepare it for subsequent testing as indicated in the test plan.

\subsection{PENETRATION TEST}

The package is placed on a rigid, flat, horizontal surface. The penetration bar is then dropped onto the package onto the center of the weakest part of the packaging specimen, so that it will hit the containment system. The drop height is predetermined, based on the type of packaging (i.e., for solids, liquids, or gases).

Complete the following steps recording all data, observations, and indicate completion of steps on Test Data Sheet 7.5, Penetration Test (refer to Appendix $C$ of this document). Use a separate test data sheet for each test unit and/or each penetration test.

\subsubsection{Initial Conditions}

The following initial conditions shall be established prior to the test:

1. The packaging has been marked, inspected, assembled, and closed (with payload) per applicable portions of Section 6.0 of this document, and as invoked by the test plan.

2. Conduct the water spray test prior to this test.

\subsubsection{Test Procedure}

1. Place the package on a drop pad or other flat, horizontal, unyielding surface in the orientation stated in the test plan. The drop height and impact point are established in the test plan; record these parameters on the appropriate test data sheet.

2. Elevate the penetration bar to the correct height above the impact area and photograph the test set-up.

3. Drop the bar freely and without restriction, impacting the package. 
WHC-SD-TP-RPT-018

Revision 1

4. Examine the impact area and photograph.

5. Examine the package for loss of containment and conditions that could result in the surface dose rate increasing more than 20 percent. Look for conditions such as compacted load or shifting or failure of shielding. Evaluate any increase of 20 percent or greater for significance. If the change is significant, mark the test as "failed."

6. Evaluate the effect of the test on the package. If no degradation to the package's effectiveness occurred, indicate "pass"; otherwise indicate "fail" and explain. Record these observations on the appropriate test data sheet.

7. Remove the package from the test set-up and prepare it for subsequent testing as indicated in the test plan.

\subsection{FREE DROP TEST}

The free drop test consists of a free-fall onto a suitable drop pad. The impact angle and orientation of the test package is predetermined and specified in the test $\mathrm{plan}$. The drop height is predetermined, based on the packaging mass, type of packaging material used (i.e., fiberboard or wood), and the physical form of the material to be placed into the packaging (i.e., solids, liquids and/or gasses). The distance of the fall will be measured from the lowest part of the packaging to the upper surface of the target and is also stated in the test plan.

Complete the following steps recording all data and observations. Indicate completion of steps on Test Data Sheet 7.6, Free Drop Test (refer to Appendix $C$ of this document). Use a separate test data sheet for each test unit and/or each drop test.

\subsubsection{Initial Conditions}

The following initial conditions shall be established prior to the test:

1. The packaging has been marked, inspected, assembled, and closed (with payload) per applicable portions of Section 6.0 of this document, and as invoked by the test plan.

2. Conduct the water spray test prior to this test. 


\section{WHC-SD-TP-RPT-018}

Revision 1

\subsubsection{Test Procedure}

1. If required, conduct a pretest shielding evaluation.

2. The impact angle, orientation, and drop height are established in the test $\mathrm{plan}$; record these parameters and sketch the rigged setup on the appropriate test data sheet.

3. Direct the riggers to establish the rigged set-up as shown on the sketch.

4. Photograph the rigged set-up showing that the drop height is correct (i.e., use a tape measure) and start the video coverage.

5. Drop the package. Following the impact, secure the video coverage.

6. Direct the riggers to clear the crane and rigging to allow for approaching the package.

7. Approach the package, examine, photograph, and videotape the damaged areas of the package. If a fluorescent powder is used, examine the damaged area and any other suspect package features by using a UV light for ease in leakage indication. A water mist/spray may be used in conjunction with the UV light for ease in visual detection of the fluorescent powder. Record the results of this on the appropriate test data sheet.

8. Examine the package for loss of containment and conditions that could result in the surface dose rate increasing more than 20 percent. Look for conditions such as compacted load or shifting or failure of shielding. Evaluate any increase of 20 percent or greater for significance. If the change is significant, mark the test as "failed."

9. If required, conduct a post-test shielding evaluation.

10. If no degradation to the package's effectiveness occurred, indicate "pass"; otherwise indicate "fail" and explain. Record these observations on the appropriate test data sheet.

11. Remove the package from the test set-up and prepare it for subsequent testing as indicated in the test plan. 
WHC-SD-TP-RPT-0.18

Revision 1

\subsection{POST-TEST PROCEDURES}

\subsection{CONTAINMENT BOUNDARY VERIFICATION}

The reduced pressure test described in Section 7.1 of this test procedure is a valid containment boundary verification method that will be used upon conclusion of testing.

\subsection{SHIELDING VERIFICATION}

If shielding exists on the tested packaging that cannot be verified by a visual examination, a measurement of the shielding effectiveness will be conducted. In most cases, the same method will be used before and after testing. The verification method used will be determined by the Project and/or Test Engineer, and will be based on the packaging design and equipment available.

\subsection{ADMINISTRATIVE/DOCUMENTATION}

The following administrative actions shall be performed at the conclusion of all evaluation and testing activities:

1. Assemble the PQCL, test plan, and all test data sheets into a data package. Review these documents with the Project Engineer to establish the conclusions of the evaluation and testing.

2. If the tested packaging is considered acceptable, a final evaluation and test report is prepared. This report should include information obtained from the $\mathrm{PQCL}$, test plan, and test data sheets. The final evaluation and test report is prepared per WHC policy and format, whether for a manufacturer-qualified or a DOE-qualified packaging.

3. Manufacturer-qualified packagings that are found to not meet DOT-7A requirements will have a letter prepared that highlights the discrepancies found during testing and evaluation. This letter is prepared by PO\&D, and will inform the applicant as to what actions may be taken to resolve any problems.

4. DOE-qualified packagings that are considered acceptable will have information pages prepared for inclusion into DOE's Test and Evaluation Document.

5. DOE-qualified packagings will additionally have the final evaluation and test report and information pages submitted to 
WHC-SD-TP-RPT-018

Revision 1

DOE/EM-76 for review and approval. Upon approval, the information pages will be incorporated into DOE's Test and Evaluation Document.

6. DOE-qual ified packagings that are found to not meet DOT-7A requirements will have a letter prepared that highlights the discrepancies found during testing and evaluation. This letter is prepared by PO\&D and is transmitted to DOE/EM-76. Additionally, P0\&D informs the applicant as to what actions may be taken to resolve any problems.

7. The completed test data sheets are added into the test plan via an ECN as described within WHC internal procedures. 
WHC-SD-TP-RPT-018

Revision 1

\subsection{REFERENCES}

49 CFR, "Transportation, " Parts 100 to 177 and Parts 178 to 199, Code of Federal Regulations, as amended.

ANSI, 1987, American National Standard for Radioactive Materials Leakage Tests on Packages for Shipment, ANSI N14.5-1987, American National Standards Institute, New York, New York.

Cruse, J. M., 1992, Test and Evaluation Document for DOT Specification 7A Type A Packaging, WHC-EP-0558, Rev. 3, Westinghouse Hanford Company, Richland, Washington.

DOE-RL, 1993, Hanford Hoisting and Rigging Manua7, DOE/RL-92-36, effective January 15, 1993, U.S. Department of Energy Rich1and Field Office, Richland, Washington.

IAEA, 1985, IAEA Safety Standards, Safety Series No. 6, Regulations for the Safe Transport of Radioactive Material, 1985 Edition, International Atomic Energy Agency, Vienna, Austria.

IAEA, 1990, IAEA Safety Guides, Safety Series No. 37, Advisory Material for the IAEA Regulations for the Safe Transport of Radioactive Material (1985 Edition), Third Edition (As Amended 1990), International Atomic Energy Agency, Vienna, Austria.

Kelly, D. L., 1995, Regulatory Compliance Guide for DOT-7A Type A f'ackaging Design, WHC-SD-TP-RPT-017, Rev. 1, Westinghouse Hanford Company, Richland, Washington.

WHC-CM-2-14, Hazardous Material Packaging and Shipping, Westinghouse Hanford Company, Richland, Washington.

WHC-CM-2-15, Training Standards, Westinghouse Hanford Company, Richland, Washington.

WHC-CM-4-2, Quality Assurance Manual, Westinghouse Hanford Company, Richland, Washington.

WHC-CM-6-1, Standard Engineering Practices, Westinghouse Hanford Company, Richland, Washington.

WHC-IP-1026, Engineering Practice Guidelines, Westinghouse Hanford Company, Richl and, Washington. 
WHC-SD-TP-RPT-018

Revision 1

\subsection{GLOSSARY}

$\begin{array}{ll}\text { CFR } & \text { Code of Federal Regulations } \\ \text { DOE } & \text { U.S. Department of Energy } \\ \text { DOE-HQ } & \text { U.S. Department of Energy-Headquarters } \\ \text { DOT } & \text { U.S. Department of Transportation } \\ \text { DOT-7A } & \text { U.S. Department of Transportation Specification 7A Type: A } \\ \text { ECN } & \text { Packaging } \\ \text { EDT } & \text { Engineering Change Notice } \\ \text { EM-76 } & \text { Office of Transportation, Emergency Management, and Ana.1ytical } \\ & \text { Services (DOE-HQ) } \\ \text { EPG } & \text { Engineering Practice Guides } \\ \text { NDT } & \text { non-destructive examination } \\ \text { PO\&D } & \text { Packaging Operations \& Development } \\ \text { PQCL } & \text { Packaging Qualification Checklist } \\ \text { PSE } & \text { Packaging Safety Engineering } \\ \text { QA } & \text { Quality Assurance } \\ \text { T\&P } & \text { Transportation \& Packaging } \\ \text { UV } & \text { ultra-violet } \\ \text { WHC } & \text { Westinghouse Hanford Company }\end{array}$


WHC-SD-TP-RPT-018

Revision 1

APPENDIX A

HANFORD PACKAGING TEST CAPABILITIES

A-1 
WHC-SD-TP-RPT-018

Revision 1

\section{CONTENTS}

Al.0 INTRODUCTION . . . . . . . . . . . . . . . . . . . . . . A-3

Al .1 FREE DROP/CORNER DROP/IMPACT TEST CAPABILITIES $\cdots \cdots$

Al.2 PUNCTURE TEST CAPABILITIES . . . . . . . . . . . . . . . A-4

Al.3 PENETRATION/PERCUSSION/BENDING TEST CAPABILITIES . . . . . . . A-4

A1.4 COMPRESSION/STACKING TEST CAPABILITIES . . . . . . . . . . . A-5

Al.5 THERMAL/HEAT TEST CAPABILITIES . . . . . . . . . . . . . . . A-5

A1.6 HEAT TEST CAPABILITIES . . . . . . . . . . . . . . . . . . . . . A-6

Al.7 COLD TEST CAPABILITIES . . . . . . . . . . . . . . . . . A-6

Al.8 VIBRATION TEST CAPABILITIES . . . . . . . . . . . . . . . . . . A-

A1.9 WATER SPRAY TEST CAPABILITIES . . . . . . . . . . . . . . . A-7

A1.10 IMMERSION TEST CAPABILITIES . . . . . . . . . . . . . . . . . . A-7

AI.11 REDUCED EXTERNAL PRESSURE/LEAKPROOFNESS TEST CAPABILITIES * - A-7

Al.12 INCREASED EXTERNAL PRESSURE TEST CAPABILITIES . . . . . . . . A-8

A1.13 HYDROSTATIC PRESSURE TEST CAPABILITIES . . . . . . . . . . . . . A-8

Al.14 SUPPORT CAPABILITIES . . . . . . . . . . . . . . . . . . A-9

A1.14.1 305 Building Support . . . . . . . . . . . . . . A-9

A1.14.2 Nondestructive Testing Support . . . . . . . . A-9 
WHC-SD-TP-RPT-018

Revision 1

\section{HANFORD PACKAGING TEST CAPABILITIES}

\section{A1.0 INTRODUCTIION}

The Department of Energy's Hanford Site is a $1,450-\mathrm{km}^{2}\left(560-\mathrm{mi}^{2}\right)$ installation located in southeastern Washington State. Established in 1943 as a plutonium production facility, Hanford's role has evolved into ore of environmental restoration and remediation. Many of these environmental restoration and remediation activities involve transportation of radioactive/hazardous materials. Packagings used for the transportation of radioactive/hazardous materials must be capable of meeting certain normal transport and hypothetical accident performance criteria. Evaluations of performance to these criteria typically involve a combination of analysis and testing. Required tests may include the free drop, puncture, penetration, stacking/compression, thermal, heat, cold, vibration, water spray, water immersion, reduced pressure, and increased pressure tests. The purpose of this document is to outline the Hanford capabilities for performing each of these tests.

\section{A1.1 FREE DROP/CORNER DROP/IMPACT TEST CAPABILITIES}

The free drop/corner drop/impact tests include the Type A free drop tests [49 CFR 173.465(c) and 49 CFR 173.466(a)(1)], the Type B free drop tests [10 CFR 71.71(c)(7), 10 CFR 71.73(c)(1)], the Type B corner drop test [10 CFR 71.71(c)(8)], the Special Form impact tests [49 CFR 173.469(b)(1) and 10 CFR 71.75(b)(1)], and the Performance-Oriented Packaging drop test [49 CFR 178.603].

These tests require that the package be dropped onto an unyielding surface. Drop height requirements vary from 0.3 to $9 \mathrm{~m}$ ( 1 to $30 \mathrm{ft}$ ). A reinforced concrete pad with a steel cover plate, and a mass ten times that of the package is generally considered to be an unyielding surface. The Westinghouse Hanford Company (WHC) has full capabilities for this type of evaluation by means of either analysis, or actual testing at any of three separate drop test facilities. The attributes for each of the drop pads are as follows:

The 305 Building test pad is an $11,868-\mathrm{kg}(26,165-1 \mathrm{~b}), 2.1-\mathrm{m}$ (84-in.) square, indoor test pad consisting of a $5-\mathrm{cm}(2-i n$.$) thick steel top plate, a$ $10-\mathrm{cm}$ (4-in.) thick steel intermediate plate, and a $61-\mathrm{cm}(2-\mathrm{ft})$ thick reinforced concrete base. The pad is located in a 4.6-m (15-ft) deep pit with a 3.0 by $3.7-\mathrm{m}$ (10 by $12-\mathrm{ft}$ ) opening. Packages can be lifted with a 1.8-metric-ton (2-ton) capacity bridge crane, or with either of two 4.5-metric-ton (5-ton) capacity bridge cranes. Maximum $1 \mathrm{ift}$ height is approximately $13.7 \mathrm{~m}(45 \mathrm{ft})$ above the pad surface. The release mechanism is a manually operated, quick-release hook. Packages up to $1,179 \mathrm{~kg}(2,600 \mathrm{lb})$ can be drop tested on this pad. 
WHC-SD-TP-RPT-018

Revision 1

The 200 Area test pad is a 64-metric-tor (71-ton), outdoor test pad consisting of a 2.1 by $3.4-\mathrm{m}$ ( 84 by $132-i n.), 38-\mathrm{mm}$ (1.5-in.) thick steel top plate, sitting on top of a reinforced concrete base that is $2.4-\mathrm{m}$ ( $8-\mathrm{ft}$ ) wide, $3.7-\mathrm{m}(12-\mathrm{ft})$ long, and $2.9-\mathrm{m}(9.5-\mathrm{ft})$ deep. Packages are 1 ifted with an appropriate capacity crane, and released from a manually operated, quick-release hook. Packages up to $6,441 \mathrm{~kg}(14,200 \mathrm{lb})$ can be drop tested on this pad.

The 300 Area pad is a 118-metric-ton (130-ton), outdoor test pad. The base of this pad consists of a $2.0-\mathrm{m}(6.5-\mathrm{ft})$ thick reinforced concrete structure, comprised of a $1.4-\mathrm{m}(4.5-\mathrm{ft})$ thick bottom section and a $0.6-\mathrm{m}$ $(2-\mathrm{ft})$ thick top section. The $1.4-\mathrm{m}(4.5-\mathrm{ft})$ thick bottom section has a width of $4.1 \mathrm{~m}(13.5 \mathrm{ft})$ and a length of $5.6 \mathrm{~m}(18.5 \mathrm{ft})$. The $0.6-\mathrm{m}(2-\mathrm{ft})$ thick top section of the concrete base is laterally centered on the bottom section of the concrete base, and is approximately $3.0-\mathrm{m}(10-\mathrm{ft})$ wide and $4.4-\mathrm{m}$ (14.5-ft) long. A $1.6-\mathrm{m}(5.4-\mathrm{ft})$ by $3.2-\mathrm{m}(10.4-\mathrm{ft}), 22-\mathrm{cm}(8.5-\mathrm{in}$.$) thick$ steel target plate has been lateraliy centered and sunk into the top surface of the concrete base. The remaining surface of the concrete base surrounding the target plate is protected by $25-\mathrm{mm}(1-\mathrm{in}$.$) thick steel aprons. Packages$ are lifted with an appropriate capacity crane, and released from a manually operated, quick-release hook. Packages up to $11,793 \mathrm{~kg}(26,000 \mathrm{lb})$ can be drop tested on this pad.

In addition to the above regulatory testing, WHC has the capability to perform extra-regulatory drop testing using locally available mobile cranes (from Neil F. Lampson, Inc.) with the ability to lift 1,008-metric-ton (1,111-ton) loads to approximately $46-\mathrm{m}$ (150-ft) high.

\section{A1.2 PUNCTURE TEST CAPABILITIES}

Puncture testing is a required Type $B$ packaging test [10 CFR 71.73(c)(3)].

This test requires the packaging to be dropped $1 \mathrm{~m}(40 \mathrm{in}$.) onto a $15-\mathrm{cm}$ (6-in.) diameter, round post that is mounted on an essentially unyielding surface.

The WHC has full capabilities for this type of evaluation by means of either analysis, or testing using a movable post, which can be placed on an appropriate test pad.

\section{A1.3 PENETRATION/PERCUSSION/BENDING TEST CAPABILITIES}

The penetration/percussion/bending tests include the Type A penetration tests [49 CFR 173.465(e) and 49 CFR 173.466(a)(2)], the Type B penetration test [10 CFR 71.71(c)(10)], the Special Form percussion tests [49 CFR 173.469 (b) (2) and 10 CFR 71.75(b)(2)] and the Special Form bending tests [49 CFR 173.469(b)(3) and 10 CFR 71.75(b)(3)]. 
WHC-SD-TP-RPT-018

Revision 1

The Type A and Type B penetration tests require a 32-mm (1.25-in.) diameter, $6-\mathrm{kg}(13.2-1 \mathrm{~b})$, round stee 1 bar to be dropped $1 \mathrm{~m}(40 \mathrm{in}$.) onto the packaging that is resting on a rigid, flat, horizontal surface that will not move while the test is being performed.

The Special Form percussion tests and bending tests are esseritially variations of the Type $A$ and Type $B$ penetration tests. These variations include the use of a smaller bar [25-mm (1-in.) diameter and $1.4 \mathrm{~kg}$ (3 1b)]. Also, for the percussion tests, the test item must rest on a $25-\mathrm{mm}$ (1-in.) thick lead surface. Finally, for the bending tests, the specimen is to be securely clamped in a horizontal position so that one half of its length protrudes from the face of the clamp.

The WHC has full capabilities for all the above variations of penetration, percussion, and bending evaluations by means of either analysis, or actual testing.

\section{A1.4 COMPRESSION/STACKING TEST CAPABILITIES}

The compression/stacking tests include the Type A stacking test [49 CFR 173.465(d)], the Type B compression test [10 CFR 71.71(c)(9)], and the Performance-Oriented Packaging stacking test [49 CFR 178.606].

The Type A stacking and Type B compression tests require uniform loading of the entire top surface of the packaging, using a load that is the greater of either five times the package weight, or $13 \mathrm{kPa}\left(1.9 \mathrm{lb} / \mathrm{in}^{2}\right)$.

The Performance-oriented Packaging stacking test requires stacking of equivalent weight packages to a minimum height of $3.0 \mathrm{~m}(10 \mathrm{ft})$.

The WHC has full capabilities for both of these types of evaluation by means of either analysis, or actual testing. Testing would typically use dead weights (such as lead bricks); however, for smaller packages, a compression testing press is available. The platens for this press are $76-\mathrm{cm}(30-i n$. square, and can be separated by a distance of $1.3 \mathrm{~m}$ (50 in.). Maximum load is $90,718 \mathrm{~kg}(200,0001 \mathrm{~b})$.

\section{A1.5 THERMAL/HEAT TEST CAPABILITIES}

The thermal/heat tests include the Type $B$ thermal test [10 CFR 71.73(c)(4)], and the Special Form heat tests [49 CFR 173.469(b)(4) and 10 CFR 71.75 (b)(4)].

The Type B thermal test requires a 30-minute exposure of the specimen to a $800^{\circ} \mathrm{C}\left(1475^{\circ} \mathrm{F}\right)$ environment. This can be accomplished using either a hydrocarbon fuel fire, or can also be accomplished in a furnace/autoclave. 
WHC-SD-TP-RPT-018

Revision 1

The Special Form heat tests require that the specimen is heated, in air, to a temperature of $800^{\circ} \mathrm{C}\left(1475^{\circ} \mathrm{F}\right)$, held at that temperature for 30 minutes, and allowed to cool. This would typically be accomplished in a furnace.

The WHC has full capabilities for this type of evaluation by means of either analysis, or actual testing. Thermal/Heat tests can be performed on small items using appropriate furnaces/autoclaves [including a heat-treating furnace with a 79-cm (31-in.) wide, $76-\mathrm{cm}(30-\mathrm{in}$.$) tall, and 1.5-\mathrm{m}(5-\mathrm{ft})$ deep cavity that can be heated to $\left.816^{\circ} \mathrm{C}\left(1500^{\circ} \mathrm{F}\right)\right]$. Due to environmental

constraints, larger items are analyzed in lieu of an actual fire test.

\section{A1. 6 HEAT TEST CAPABILITIES}

The heat test is a required Type B test [10 CFR 71.71(c)(1)].

This test requires an ambient temperature of $38^{\circ} \mathrm{C}\left(100^{\circ} \mathrm{F}\right)$ followed by a 12-hour period with insolation up to $800 \mathrm{~g} \mathrm{cal} / \mathrm{cm}^{2}$.

The WHC has full capabilities for this type of evaluation. Packagings are typically analyzed in lieu of actual testing; however, several environmental chambers are available. Typical chamber dimensions are $91 \mathrm{~cm}$ ( $3 \mathrm{ft}$ ) on each side. Temperatures of -68 to $+177^{\circ} \mathrm{C}\left(-90\right.$ to $\left.+350^{\circ} \mathrm{F}\right)$ and relative humidities of 20 to 95 percent are achievable.

\section{Al.7 COLD TEST CAPABILITIES}

The cold test is a required Type B test [10 CFR $71.71(\mathrm{c})(2)]$.

This test requires exposure of the packaging to a temperature of $-40^{\circ} \mathrm{C}$ $\left(-40^{\circ} \mathrm{F}\right)$, in still air, in the shade.

The WHC has full capabilities for this type of evaluation. Packagings are typically analyzed in lieu of actual testing; however, several environmental chambers are available. Typical chamber dimensions are $91 \mathrm{~cm}$ $(3 \mathrm{ft})$ on each side. Temperatures of -68 to $+177^{\circ} \mathrm{C}\left(-90\right.$ to $\left.+350^{\circ} \mathrm{F}\right)$ and relative humidities of 20 to 95 percent are achievable.

\section{A1.8 VIBRATION TEST CAPABILITIES}

Vibration tests include the Type A vibration requirement [49 CFR $173.410(\mathrm{f})]$, Type B vibration test [10 CFR $71.71(\mathrm{c})(5)]$, and the Performance-Oriented Packaging vibration test [49 CFR 178.608].

The Type A vibration requirement requires the package meet the requirements as a Performance-Oriented Package for non-radioactive materials. 
WHC-SD-TP-RPT-018

Revision 1

The Type B vibration test requires exposure of the package to vibration normally incident to transportation.

The Performance-Oriented Packaging vibration test requires $\mathrm{placing}$ the samples on a vibrating platform that has a vertical or rotary, double amplitude (peak-to-peak displacement) of $25 \mathrm{mrn}$ (1 in.).

The WHC has full capability for this type of evaluation by means of either analysis, or by actual testing using a vibration table. Several vibration tables are available, including one of the largest, that has a 137 by $145-\mathrm{cm}$ ( 54 by $57-$ in.) table. Frequency is adjustable from 3 to 25 hertz, with a maximum double amplitude of $32 \mathrm{~mm}$ (1.25 in.), adjustable from vertical to horizontal. The table is capable of testing at accelerations up to five times gravity for specimens $227 \mathrm{~kg}(500 \mathrm{lb})$ or less, decreasing linearly to 1.4 times gravity for a maximum specimen weight of $4,536 \mathrm{~kg}(10,000 \mathrm{lb})$.

\section{A1.9 WATER SPRAY TEST CAPABILITIES}

The water spray tests include the Type A water spray test [49 CFR 173.465(b)], and the Type B water spray test [10 CFR 71.71(c)(6)].

These tests require exposure of the package to a water spray of 5-cm (2-in.) per hour for one hour.

The WHC has full capabilities for this type of evaluation by means of either analysis, or actual testing.

\section{A1.10 IMMERSION TEST CAPABILITIES}

The immersion test is a required Type B test [10 CFR 71.73(c)(6)].

This test requires exposure of the packaging to a water pressure corresponding to immersion depths from 0.9 to $15 \mathrm{~m}$ ( 3 to $50 \mathrm{ft}$ ).

The WHC has full capabilities for this type of evaluation. Test items are analyzed in lieu of an actual immersion test.

\section{A1.11 REDUCED EXTERNAL PRESSURE/LEAKPROOFNESS TEST CAPABILITIES}

Reduced external pressure/leakproofness tests include the Type $A$ reduced externa] pressure test [49 CFR 173.412(f)], the Type B reduced externa] pressure test [10 CFR $71.71(\mathrm{c})(3)]$, and the Performance-Oriented Packaging leakproofness test [49 CFR 178.604].

The Type $A$ and Type $B$ reduced external pressure tests require reduction of the absolute external pressure to $25 \mathrm{kPa}(3.6 \mathrm{psi})$, and can be simulated by increasing the internal gauge pressure to $78.0 \mathrm{kPa}$ (11.3 psi). 
WHC-SD-TP-RPT-018

Revision 1

The Performance-Oriented Packaging leakproofness test requires that the internal gauge pressure be increased to 20 or $30 \mathrm{kPa}$ ( 3 or $4 \mathrm{psi}$ ), depending on the packing group.

The WHC has full capabilities for this type of evaluation by means of either analysis, or actual testing (including helium leak testing). Increased internal pressures can be achieved using an appropriately constructed test

rig. Reduced external pressures can be achieved using an appropriately sized vacuum chamber.

\section{A1.12 INCREASED EXTERNAL PRESSURE TEST CAPABILITIES}

The increased external pressure test is a required Type $B$ test [10 CFR $71.71(\mathrm{c})(4)]$.

This test requires increasing the absolute external pressure of the packaging to $140 \mathrm{kPa}$ (20 psi).

The WHC has full capabilities for this type of evaluation by means of either analysis, or actual testing. A $1.4-\mathrm{m}^{3}\left(49.4-\mathrm{ft}^{3}\right)$ vacuum/pressure chamber is available that is capable of applying an absolute pressure of over $350 \mathrm{kPa}$ (50 psi).

\section{Al. 13 HYDROSTATIC PRESSURE TEST CAPABILITIES}

The hydrostatic pressure test is a required Performance-0riented Packaging test [49 CFR 178.605].

This test requires pressurizing a liquid inside of the package. Test pressures depend on vapor pressure of the payload, although minimum gauge pressure is $100 \mathrm{kPa}$ (15 psi).

The WHC has full capabilities for this type of evaluation by means of either analysis, or actual testing using an appropriately constructed test rig.

\section{A1.14 SUPPORT CAPABILITIES}

In addition to the stated testing capabilities, the WHC has a full complement of support capabilities, including a wide spectrum of test instrumentation with calibrations traceable to the National Institute of Standards and Testing, numerous computer analys is techniques (including super computer capability), still photography, videography (including high-speed), and full non-destructive test capabilities.

Shielding evaluations requiring the utilization of neutron sources have been achieved through cooperation of other Hanford contractors.

\section{A-8}


WHC-SD-TP-RPT-018

Revision 1

\section{A1.14.1 305 Building Support}

Water Spray Testing - The 305 Building has two small cylindrical tanks that may be used to conduct indoor testing. One tank is $1.83 \mathrm{~m}$ high by $3.66 \mathrm{~m}$ diameter ( $6 \mathrm{ft}$ high by $12 \mathrm{ft}$ diameter); the other is $1.52 \mathrm{~m}$ high by $3.05 \mathrm{~m}$ diameter ( $5 \mathrm{ft}$ high by $10 \mathrm{ft}$ diameter). In addition to these tanks, a 7 arge outdoor tank exists and is $5.18 \mathrm{~m}$ by $5.18 \mathrm{~m}(17 \mathrm{ft}$ by $17 \mathrm{ft})$. Larger packages may be sprayed by using fire hoses.

Reduced External Pressure/Leakproof Testing - The 305 Building currently uses the Nalgene vacuum chamber. This chamber is $30.5 \mathrm{~cm}$ high by $30.5 \mathrm{~cm}$ diameter (12 in. high by 12 in. diameter), and has the capability of drawing pressure to $25 \mathrm{kPa}(3.6 \mathrm{psia})$. Capabilities are not 1 imited, however, and customers' needs will be met to what is specifically needed.

Environmental Chamber - The chamber in the 305 Building is $94 \mathrm{~cm}$ wide by $94 \mathrm{~cm}$ deep by $94 \mathrm{~cm}$ high ( $37 \mathrm{in}$. wide by $37 \mathrm{in}$. deep by $37 \mathrm{in}$. high).

\section{A1.14.2 Nondestructive Testing Support}

306E Building - The 306E Building, located in the 300 Area, houses various equipment that may be utilized for nondestructive testing purposes. This building is $4140 \mathrm{~m}^{2}\left(46,000 \mathrm{ft}^{2}\right)$ and is divided into two bay areas where a total of two overhead cranes may be utilized. One of the bay areas has a $14.63 \mathrm{~m}$ (48 ft) deep pit that was originally built to test Fast Flux Test Facility (FFTF) components that were $12.2 \mathrm{~m}(40 \mathrm{ft})$ in length. Today, this pit could be utilized for drop testing, especially for a package that was quite long.

The $306 \mathrm{E}$ Building also has a highly specialized welding lab, electronics $1 \mathrm{ab}$, machine shop, gas analyzer, and cleaning bank tanks. In particular, the cleaning bank tanks are $3.66 \mathrm{~m}(12 \mathrm{ft})$ deep so that long assemblies that require cleaning before we1ding can be cleaned in a nitric acid, hot water, and cold water bath.

A Quality Control (QC) receiving and inspection area also exists in this building. Materials are checked against manufacturer and drawing requirements in this area. Some of the equipment utilized here are optical capacitors and calibrated precision measuring gauges.

Nondestructive Equipment Testing Group - The Nondestructive Equipment (NDE) Testing Group has a staff of trained and certified individuals. The Leve1 1 and 2 program personnel are certified in the American Society of Nondestructive Testing (ASNT), SNT-TC-1A (National document certified to). Level 3 program personnel are certified against National Examinations.

\footnotetext{
${ }^{1}$ Nalgene is a trademark of Sybron Corporation.
} 
WHC-SD-TP-RPT-018

Revision 1

The NDE organization has a Welch-Allen color videoscope that is $0.95 \mathrm{~cm}$ (0.375 in.) in diameter, and underground survey equipment capable of detecting metals (i.e., rebar) at about a ground depth of $3.05 \mathrm{~m}(10 \mathrm{ft})$. NDE Testing primarily consists of the following: Radiography (x-rays), ultrasonic, magnetic particle, penetrant, leak test, and Eddy current. A brief explanation of each is listed below:

Radiography: Used for internal component placement, volumetric examination, test articles, castings, welds. One new radiographic unit exists and has the capability of $450 \mathrm{kV}$. A field unit is available with capabilities of $200 \mathrm{kV}$. Two isotopic sources can be utilized, Iridium 192 and Cobalt 60 . A Kodak film processor is used for developing $x$-rays.

U1trasonic: Used for internal defect location, raw material inspection, thickness gauging, and volumetric examination. Equipment range is about a minimum thickness of 10 mills to unlimited thickness (meters/feet).

Magnetic Particle: Testing is only done on ferrous-type materials, such as carbon stee1, in order to conduct surface examination. This type of testing is used for structural-type inspections.

Penetrant: Many materials exist that are used to detect surface indications on non-porous surfaces.

Leak Test: Conducted on welds, seals, and fittings; reactor components; tanks and vessels; refrigeration units. The current helium leak test unit is capable of a range from $10^{-3} \mathrm{~atm} \mathrm{cc} / \mathrm{sec}$ to $10^{-10} \mathrm{~atm} \mathrm{cc} / \mathrm{sec}$. Two new units will arrive soon and have the range capability of $1.0 \mathrm{~atm}$ $\mathrm{cc} / \mathrm{sec}$ to $2 \times 10^{-10} \mathrm{~atm} \mathrm{cc} / \mathrm{sec}$. Pressure decay, vacuum decay, and bubble testing may also be conducted.

Eddy Current: This testing is primarily used to sort out various types of materials that appear to be the same, and are not. This type of testing is sensitive to resistivity of parts. 
WHC-SD-TP-RPT-018

Revision 1

APPENDIX B

EXAMPLE OUTLINE - TEST PLAN

B-1 
WHC-SD-TP-RPT-018

Revision 1

\section{CONTENTS}

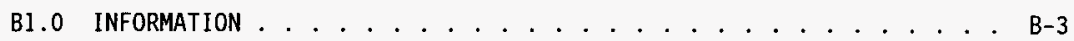

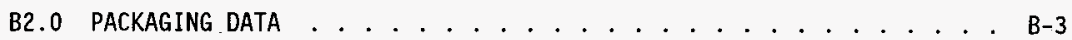

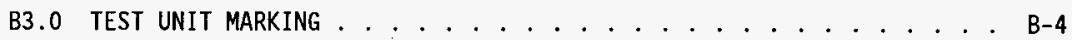

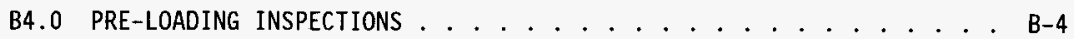

B5.0 SIMULATED PAYLOAD . . . . . . . . . . . . . . . . B-4

B6.0 DESIGN CONFIRMATION SEQUENCE .............. . . . . . . B6.1 CONTAINMENT BOUNDARY VERIFICATION . . . . . . . . . . . B6.2 SHIELDING VERIFICATION . . . . . . . . . . . . . B-4

B7.0 TEST SEQUENCE: TEST UNITS $[X X]-T U-01$ THROUGH $[X X]-T U-[N N] \ldots \ldots-. .8$ B7.1 ASSEMBLY, LOADING, AND CLOSURE ........... B-6 B7.2 VIBRATION TEST . . . . . . . . . . . . . B-6 B7.3 WATER SPRAY TEST . . . . . . . . . . . . . . B-7 B7.4 STACKING TEST . . . . . . . . . . . . . . B7.5 PENETRATION TEST . . . . . . . . . . . . . . . . . B-7 B7.6 FREE DROP TEST $\ldots \ldots \ldots$

B8.0 POST TEST ACTIONS - PACKAGING .............. . . . . . . . .

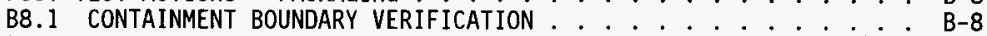

B8.2 SHIELDING VERIFICATION . . . . . . . . . . . . . . .

B9.0 POST TEST ACTIONS - ADMINISTRATIVE . . . . . . . . . . B-9

B10.0 TEST PLAN APPENDICES . . . . . . . . . . . . . . B-9 
WHC-SD-TP-RPT-018

Revision 1

\section{EXAMPLE OUTLINE - TEST PLAN}

The documentation presented in this section is for informational purposes only and is intended to only be used as a model when developing a test plan appropriate to a specific packaging that will be undergoing D0T-7A Type $A$ package testing by WHC.

\subsection{INFORMATION}

Provide and introductory statement about the packaging being tested. Identify the packaging being tested and provide a brief statement of what the component items are; identify what the package is being qualified for and what material is intended for shipment. Identify who the designer and developer of the packaging is, and who is conducting the performance testing and design review. The following should be included in this section:

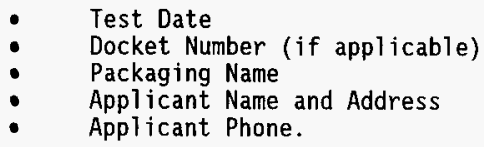

\section{B2.0 PACKAGING DATA}

This section should include detailed information about the packaging configuration(s) being tested. The following should be identified in this section:

- Packaging manufacturer

- Manufacturer drawing number

- Gross weight

- Net weight

- Product fill weight, if applicable

- Contents intended for shipment (solid, liquid, or gas)

- Identify specific gravity, if applicable

- Dimensions (overali and component)

- Part numbers for component items

- Weight of component items, if applicable

- Simulated payload to be used for testing. 
WHC-SD-TP-RPT-018

Revision 1

\section{B3.0 TEST UNIT MARKING}

1. Identify what test packagings and materials will be supplied by the test applicant.

2. Mark each test unit in accordance with Section 6.3 of this test

procedure. Identify the component parts to be marked.

3. List the test units by a unique test unit number, and note the configuration of each if more than one packaging configuration is being tested.

For example: $\begin{array}{ll} & {[\mathrm{xx}]-\mathrm{TU}-01} \\ & {[\mathrm{xx}]-\mathrm{TU}-02} \\ & {[\mathrm{xx}]-\mathrm{TU}-03} \\ & {[\mathrm{xx}]-\mathrm{TU}-\mathrm{NN} \text { (additional, as needed). }}\end{array}$

\section{B4.0 PRE-LOADING INSPECTIONS}

1. Perform preloading inspections on each test unit per Section 6.4 of this test procedure and record the data on the appropriate Test Data Sheet (either 6.4.1, 6.4.2 and 6.4.3 as shown in Appendix $C$ of this procedure). Use a separate set for each test unit.

\section{B5.0 SIMULATED PAYLOAD}

1. Describe the simulated payload to be used for each test unit. If different packaging configurations are to be tested, be sure to identify the simulated payload for each configuration.

\section{B6.0 DESIGN CONFIRMATION SEQUENCE}

\section{B6. 1 CONTAINMENT BOUNDARY VERIFICATION}

Identify the verification method to be used (refer to Section 7.1 of this test procedure). Record data on the appropriate Test Data Sheet (either 7.1.2 or 7.1 .3 as shown in Appendix $C$ of this procedure). Use a separate test data sheet for each test unit.

\section{B6.2 SHIELDING VERIFICATION}

Identify if shielding is a component of the packaging being tested. If there is no shielding, identify what components make up the containment system. Identify what checks will be made on specific components to ensure containment is achieved and there is no release of simulated contents. 
WHC-SD-TP-RPT-018

Revision 1

If shielding exists, identify the verification method to be used (refer to Section 7.1 of this test procedure). Record data on the appropriate Test Data Sheet (either 7.1.2 or 7.1 .3 as shown in Appendix $C$ of this procedure). Use a separate test data sheet for each test unit.

\section{B7.0 TEST SEQUENCE: TEST UNITS [XX]-TU-01 THROUGH [XX]-TU-[NN]}

The test plan will identify each test in accordance with Section 6.3 of this test procedure. Identification of tests will incorporate an "event" number, consisting of the test unit designation followed by a sequential integer indicating the test sequence.

$$
\begin{array}{ll}
\text { Example: } & X X-T U-01-1 \\
& X X-T U-01-2 \\
& X X-T U-01-3
\end{array}
$$

Identify what is done to the packagings prior to actual testing. The following statements, for example, could be used:

"Test units will undergo marking, inspection, and assembly. Each test unit will be subjected to the water spray test as a prerequisite to any other testing (with the exception of the vibration test) unless it is determined by the Test and Project Engineer that after the water spray test is conducted on the first test unit that this test does not result in any significant deterioration of the packaging."

"The packages must perform adequately when subjected to the applicable performance tests. There should be evidence that the integrity of the packaging would remain with no release of the hazardous materials to the environment (49 CFR 173.24), no loss or dispersal of radioactive contents, and no significant increase in the radiation levels recorded or calculated at the external surfaces for the condition before the test [49 CFR 173.412(j)]."

"Each configuration will be considered a unique package for testing purposes. Failure of one configuration does not eliminate the further satisfactory completion of testing for the remaining configurations. In the event of a failed configuration, the Test and Project Engineer, in conjunction with the test applicant, may make an evaluation in order to determine whether an alternative internal packaging arrangement may warrant further testing."

Identify what the testing sequence will be, referencing the specific sections within the test plan appropriate to each specific test. This can easily be accomplished by using tabulated information. Refer to Table 1 as an example. 
WHC-SD-TP-RPT-018

Revision 1

Table 1. Testing Sequence.

\begin{tabular}{|c|c|c|}
\hline Type of test & $\begin{array}{c}\text { Reference } \\
\text { (within the specific } \\
\text { test plan) }\end{array}$ & $\begin{array}{c}\text { Test unit } \\
\text { number }\end{array}$ \\
\hline Vibration test & Section 7.2 & $\begin{array}{l}x: T-T U-x X \\
x: X-T U-x X \\
x: T-T U-x X \\
\end{array}$ \\
\hline Water spray test ${ }^{a}$ & Section 7.3 & $\begin{array}{l}x x-T U-x x^{6} \\
\text { through } \\
x x-T U-x x \\
\end{array}$ \\
\hline Stack test & Section 7.4 & $x x-T U-x x$ \\
\hline Penetration test $-1.0 \mathrm{~m}(3.3 \mathrm{ft})$ & Section 7.5 & $x x-T U-x x$ \\
\hline Drop test - $1.2 \mathrm{~m}(4 \mathrm{ft})$ & Section 7.6 & $\begin{array}{c}x x-T U-x x \\
\text { through } \\
x x-T U-x x \\
\end{array}$ \\
\hline
\end{tabular}

a The time interval between the end of the water spray test and the beginning of the next test shall be such that the water has soaked in to the maximum extent without appreciable drying of the exterior of the package. The time interval is 2 hours if the spray is applied simultaneously from four different directions. Other tests will follow immediately if the spray is applied consecutively from each of the four directions. Testing will need to be carefully scheduled to ensure the time period is not exceeded by a significant time interval to the extent that the exterior of the package dries out.

${ }^{b}$ If after the first water spray test, the Test Engineer determines that the water spray test does not result in any significant deterioration of the packaging, no further water spray tests will be performed on packagings before testing.

\section{B7. 1 ASSEMBLY, LOADING, AND CLOSURE}

Describe the test unit number and event number. Describe the assembly, loading, and closure event specific to the test units and event numbers. Take pretest photographs.

\section{B7.2 VIBRATION TEST}

Describe the test unit number and event number. Assemble, load, and close the packaging with simulated payload in position and in accordance with the test plan. Photograph the pretest condition. Perform the vibration 
WHC-SD-TP-RPT-018

Revision 1

testing in accordance with 49 CFR 178.608 and Section 7.2 of this test procedure. Photograph the post test conditions. Record the results on Test Data Sheet 7.2 as shown in Appendix $C$ of this procedure. Use a separate data sheet for each test unit.

\section{B7.3 WATER SPRAY TEST}

Describe the test unit number and event number. Assemble, load, and close the packaging with simulated payload in position and in accordance with the test plan. Photograph the pretest condition. Perform the water spray test in accordance with 49 CFR 173.465 (b) and Section 7.3 of this test procedure. Photograph the post test conditions. Record the results on Test Data Sheet 7.3 as shown in Appendix $C$ of this procedure. Use a separate data sheet for each test unit.

\section{B7.4 STACKING TEST}

State the compressive load to be used, and note how the load was determined (i.e., show the calculations performed).

Describe the test unit number and event number. Assemble, load, and close the packaging with simulated payload in position in accordance with the test plan. Photograph the pretest condition. Perform the stacking test in accordance with 49 CFR 173.465 (d) and Section 7.4 of this test procedure.

Take photographs of the package at the end of the 24-hour test period prior to removing the compressive load and after removal of the load.

Measurements should be taken to determine if there are any changes in height of the packaging. Record the results on Test Data Sheet 7.4 as shown in Appendix $C$ of this procedure. Use a separate data sheet for each test unit.

\section{B7.5 PENETRATION TEST}

Describe the test unit number and event number. Assemble, load, and close the packaging with simulated payload in position and in accordance with the test plan. Photograph the pretest condition. Perform the penetration test in accordance with 49 CFR 173.465 (e) and Section 7.5 of this test procedure.

The following information should be included:

Drop Height of Penetration Bar: $\quad 1.0 \mathrm{~m}(3.3 \mathrm{ft})$ solids

$1.7 \mathrm{~m}(5.5 \mathrm{ft})$ liquids and/or gasses 
WHC-SD-TP-RPT-018

Revision 1

Impact Point: Describe the weakest part of the packaging to be impacted so as to penetrate the containment system.

Photograph the post test conditions. Record the results on Test Data Sheet 7.5 as shown in Appendix $C$ of this procedure. Use a separate data sheet for each test unit.

Note that the penetration bar drop heights vary depending on packaging contents. Perform additional penetration tests as required.

\section{B7.6 FREE DROP TEST}

Describe the test unit number and event number. Assemble, load, and close the packaging with simulated payload in position and in accordance with the test plan. Photograph and videotape the pretest condition. Perform the free drop test in accordance with 49 CFR 173.465(c) and Section 7.6 of this test procedure.

The following information should be included:

Drop Height: Varies depending on packaging mass, materials of construction, and intended contents.

Impact Angle: Reference the angle of the packaging to be dropped in degree of orientation (i.e., $45^{\circ}$ angle).

Orientation: Reference the feature to be attacked, and the angle (i.e., flat on the top; center-of-gravity to impact the top corner).

Photograph the post test conditions. Record the results on Test Data Sheet 7.6 as shown in Appendix $C$ of this procedure. Use a separate data sheet for each test unit.

Note that additional drop heights may be required depending on materials of construction and intended contents. Perform additional drop tests as required.

\section{B8.0 POST TEST ACTIONS -. PACKAGING}

\section{B8. I CONTAINMENT BOUNDARY VERIFICATION}

Identify what checks will be performed to ensure containment is achieved and there is no release of simulated contents. 
WHC-SD-TP-RPT-018

Revision 1

\section{B8.2 SHIELDING VERIFICATION}

Identify what checks will be performed on shielding to ensure containment is achieved and there is no release of simulated contents.

\section{B9.0 POST TEST ACTIONS - ADMINISTRATIVE}

Data, including measurements when specified, will be thoroughly documented on the appropriate test data sheets after each test has been performed. Photographs of damage and video coverage of the tests performed will also be used as documentation. Perform post test activities as outlined in Section 8.0 of this procedure.

\section{B10.0 TEST PLAN APPENDICES}

An appendix should be incorporated into the test $p l$ an to graphically show the packaging configuration(s) being tested. An additionat appendix should be included that describes the opening, loading, and closure procedure used during packaging testing.

Upon conclusion of testing, the completed test data sheets shall be added into the test plan document via an Engineering Change Notice per Westinghouse Hanford Company procedures. 
WHC-SD-TP-RPT-018

Revision 1

APPENDIX C

TEST DATA SHEETS 
WHC-SD-TP-RPT-018

Revision 1

DOT-7A PROGRAM

TEST DATA SHEET 6.4.1

PACKAGING VISUAL INSPECTIONS

Perform inspections per procedure Section 6.4.1.

Test Engineer:
DOCKET :

TEST UNIT NO:

Date:

Component :

Remarks :

Remarks:

Component:

Accept [ ]

Reject [ ]

Remarks: 
WHC-SD-TP-RPT-018

Revision 1

DOT-7A PROGRAM

TEST DATA SHEET 6.4.2

DOCKET :

PACKAGING COMPONENT WEIGHTS

Page 1 of 2

Measure major component weights and record per procedure Section 6.4.2.

Test Engineer:

Date:

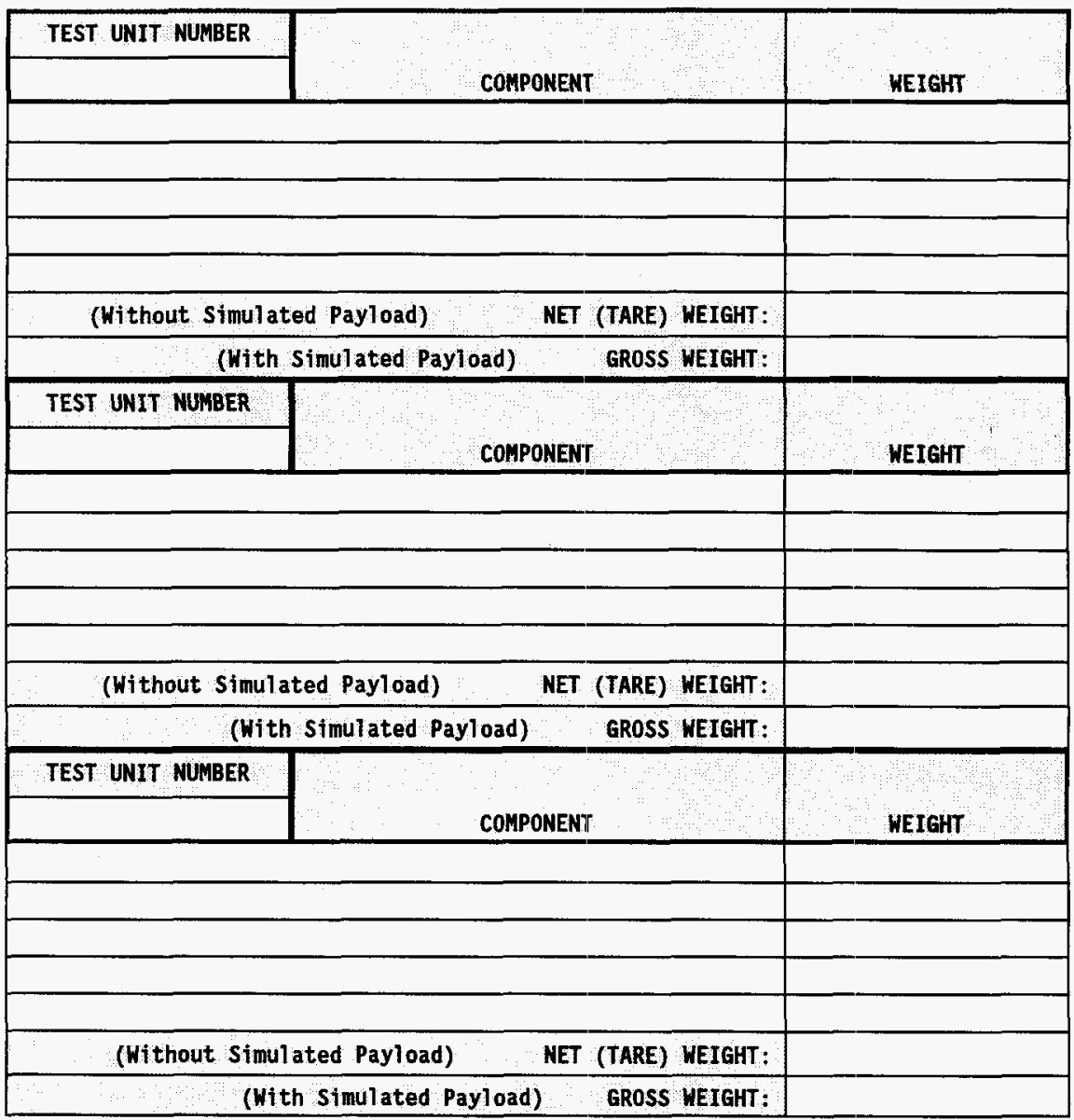


WHC-SD-TP-RPT-018

Revision 1

DOT-7A PROGRAM

TEST DATA SHEET 6.4 .2

DOCKET :

PACKAGING COMPONENT WEIGHTS

Page 2 of 2

Measure major component weights and record per procedure Section 6.4.2

Test Engineer:

Date:

\section{EQUIPMENT NOTES:}

Description:

Serial No.:

Calibration No.:

Calibration Expiration:

Accuracy:

\section{EQUIPMENT NOTES:}

Description:

Serial No.:

Calibration No.:

Calibration Expiration:

Accuracy:

REMARKS: 
TEST DATA SHEET 6.4 .3

\section{PACKAGING COMPONENT WALL THICKNESS}

DOCKET:

Measure component wall thickness and any significant dimensions identified per the Test Plan. Record information per procedure Section 6.4.3.

Test Engineer:

Date:

\begin{tabular}{|c|c|c|c|}
\hline TEST UNIT NUMBER & \multicolumn{3}{|c|}{ COMPONENT } \\
\hline \multicolumn{4}{|l|}{ FEATURE OR LOCATION: } \\
\hline LENGTH & WIDTH & & HEIGHT \\
\hline THICKNESS: & & \multicolumn{2}{|l|}{ DIAMETER: } \\
\hline OTHER: & & & \\
\hline
\end{tabular}

\begin{tabular}{|c|c|c|c|}
\hline TEST UNIT NUMBER & \multicolumn{3}{|c|}{ COMPONENT } \\
\hline & \multicolumn{3}{|c|}{} \\
\hline FEATURE OR LOCATION: & WIDTH & HEIGHT \\
\hline LENGTH & & & \\
\hline & & DIAMETER: & \\
\hline THICKNESS: & & & \\
\hline OTHER: & & & \\
\hline
\end{tabular}

\begin{tabular}{|c|c|c|c|}
\hline TEST UNIT NUMBER & \multicolumn{3}{|c|}{ COMPONENT } \\
\hline FEATURE OR LOCATION: & \multicolumn{3}{|c|}{} \\
\hline LENGTH & WIDTH & HEIGHT \\
\hline THICKNESS: & & & \\
\hline OTHER: & & DIAMETER: : & \\
\hline
\end{tabular}


Measure component wall thickness and any significant dimensions identified per the Test Plan. Record information per procedure Section 6.4.3.

Test Engineer:

Date:

\section{EQUIPNENT NOTES:}

Description:

Serial No.:

Calibration No.:

Calibration Expiration:

Accuracy:

EQUTPNENT NOTES:

Description:

Serial No.:

Calibration No.:

Calibration Expiration:

Accuracy:

\section{REMARKS:}


DOCKET:

TEST DATA SHEET 7.1.2

REDUCED PRESSURE TEST - PRESSURE ELEVATION METHOD

TEST UNIT NO:

Perform the reduced pressure test per the test plan, and record data per Section 7.1.2.

Test Engineer:

Date:

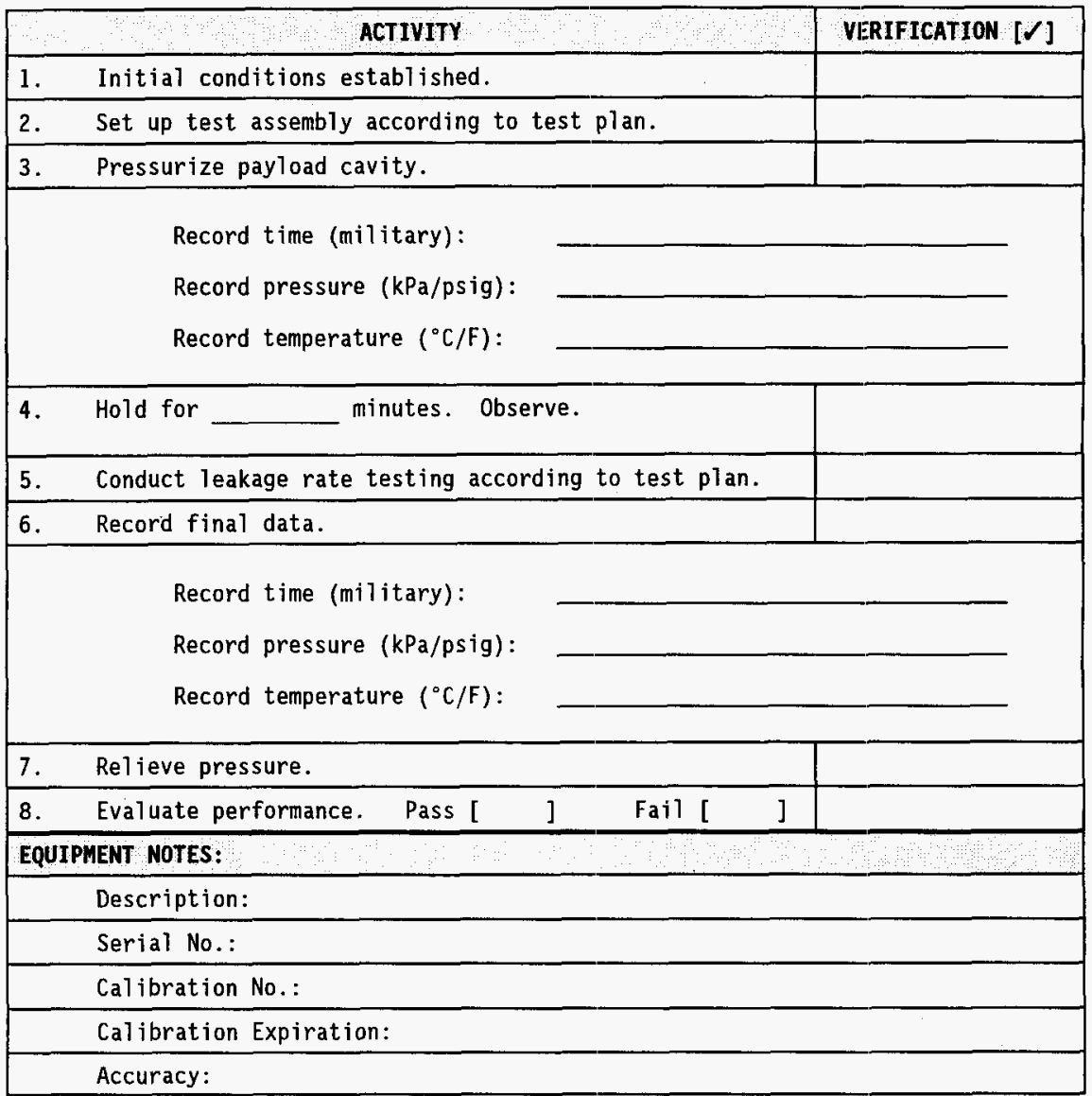


WHC-SD-TP-RPT-018

Revision 1

DOT-7A PROGRAM

DOCKET :

TEST DATA SHEET 7.1 .3

REDUCED PRESSURE TEST - PRESSURE REDUCTION METHOD

TEST UNIT NO:

Perform the reduced pressure test per the test plan, and record data per Section 7.1.3.

Test Engineer:

Date:

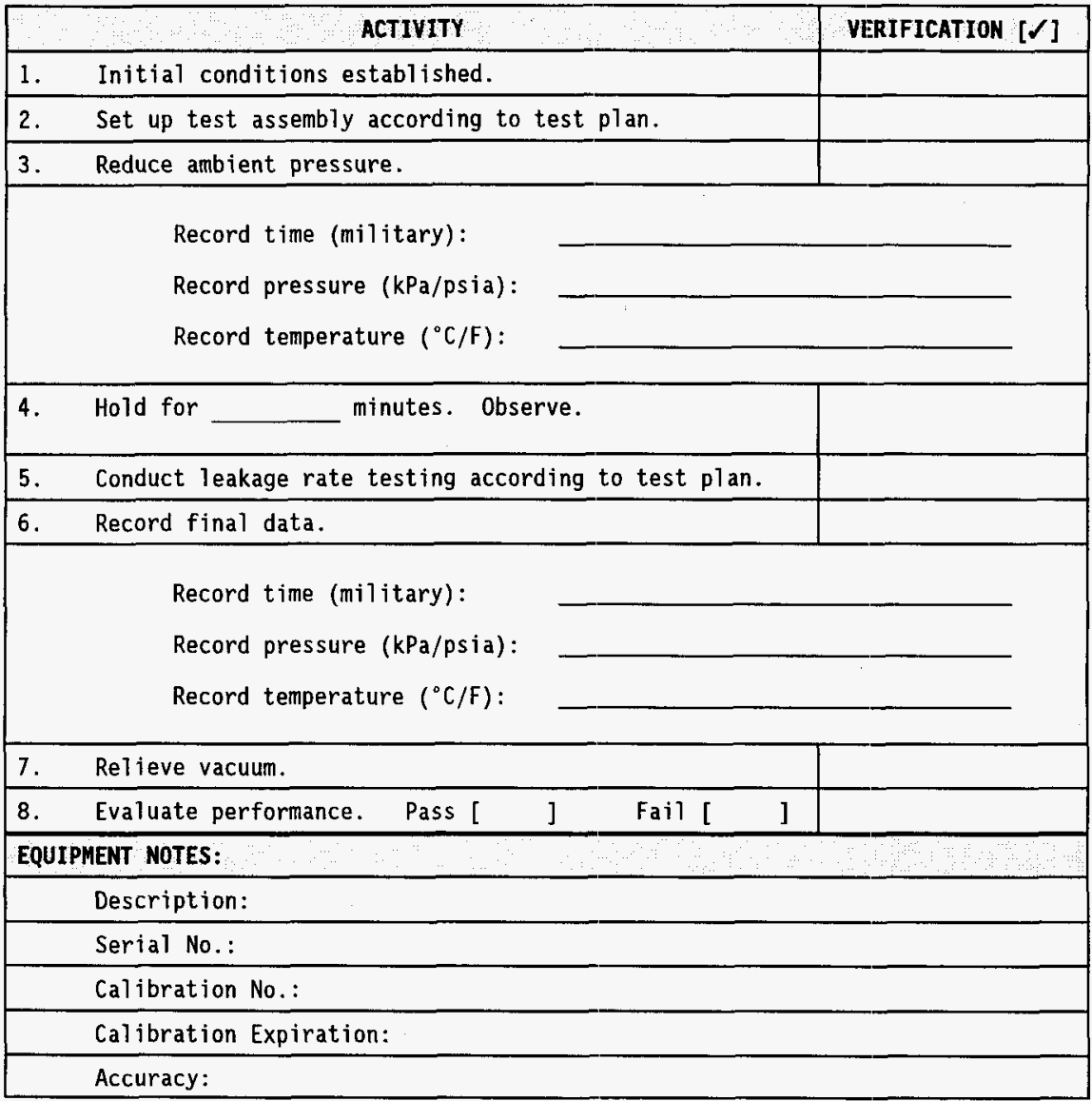


DOT-7A PROGRAM

TEST DATA SHEET 7.2

VIBRATION TEST
DOCKET :

TEST UNIT NO:

Perform the vibration test per 49 CFR 178.608, "Vibration Standards," and record data per Section 7.2.

Test Engineer:

Date:

\section{ACTIVITY}

1. Initial conditions established.

2. Set up test assembly according to test plan. Photograph.

3. Start vibration.

Record time (military):

4. Maintain vibration; observe; photograph.

5. Stop vibration; secure equipment.

Record time (military):

6. Turn package on its side and observe for leakage.

7. Photograph results.

8. Evaluate performance. Pass [ ] Fail [ ]

EQUIPNENT NOTES:

Description:

Serial No.:

Calibration No.:

Calibration Expiration:

Accuracy:

REMARKS: 
WHC-SD-TP-RPT-018

Revision 1

DOT-7A PROGRAM

DOCKET:

TEST DATA SHEET 7.3

WATER SPRAY TEST

TEST UNIT NO:

Perform the water spray test and record data per section 7.3 .

Test Engineer:

Date:

\section{ACTIVITY}

VERIFICATION

$[\checkmark]$

1. Initial conditions established.

2. Set up test assembly according to test plan. Photograph.

3. Start water spray.

Record time (military):

4. Maintain water spray; observe; photograph.

5. Stop water spray; secure equipment.

Record time (military):

6. Photograph results.

7. Evaluate performance. Pass [ ] Fai1 [ ]

REMARKS:

$C-10$ 
DOT-7A PROGRAM

TEST DATA SHEET 7.4

STACKING TEST
DOCKET :

TEST UNIT NO:

Date:

Test Engineer:

Section 7.4 .

(n)

\section{ACTIVITY}

1. Initial conditions established.

2. Set up test assembly according to test plan.

Test load $(\mathrm{kg} / \mathrm{lb})$ :

3. Load package; record time.

Record time (military):

4. Hold (24 hours); observe; photograph.

5. Unload weights from package; record time.

6. Photograph results.

7. Evaluate performance.

REMARKS:

\section{Record time (military):}

VERIFICATION

[ऽ]

\section{REMARKS:}


DOT-7A PROGRAM

TEST DATA SHEET 7.5

PENETRATION TEST

Perform the penetration test and record data per Section 7.5.

Test Engineer:

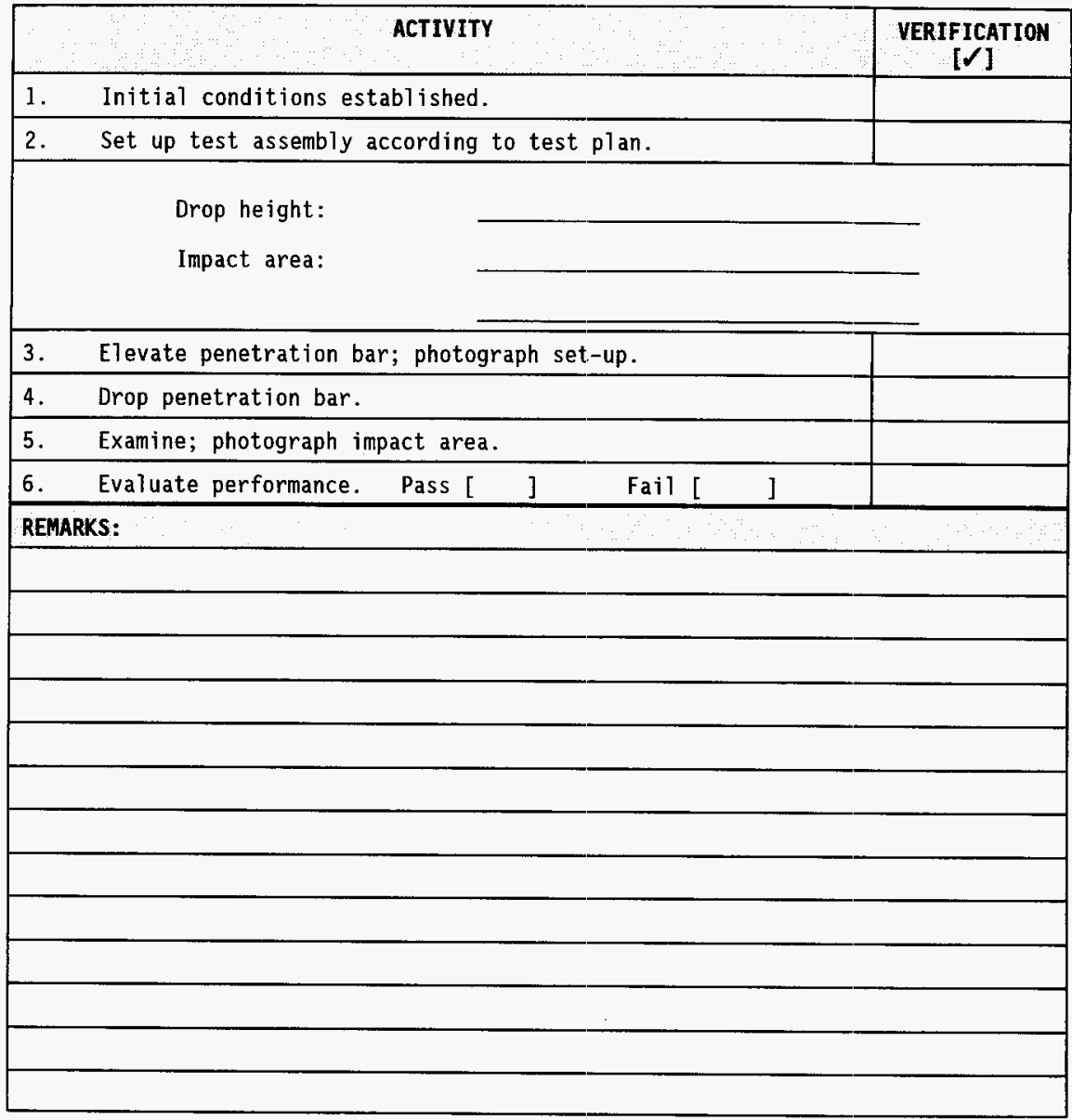

DOCKET:

TEST UNIT NO:

Date:

VERIFICATION 
Perform the free drop test and record data per Section 7.6.

Test Engineer:

Date:

\section{ACT IVITY}

VERIFICATION

$[\checkmark]$

1. Initial conditions established.

2. Set up test assembly according to test plan.

Drop height:

Impact angle:

orientation:

3. Sketch drop orientation: $(\mathrm{cm} / \mathrm{in})$

(degrees) 
WHC-SD-TP-RPT-018

Revision 1

DOT-7A PROGRAM

TEST DATA SHEET 7.6

FREE DROP TEST
DOCKET :

TEST UNIT NO:

Page 2 of 2

Perform the free drop test and record data per section 7.6.

Test Engineer:

Date:

\section{ACTIVITY}

VERIFICATION

$[\checkmark]$

4. Rig package.

5. Photograph set-up; start video coverage.

6. Drop package; secure video.

7. Clear drop area for approach.

8. Examine; photograph; videotape package damage.

9. Evaluate performance. Pass [ ] Fail [

RENARKS: 